\title{
Cloud Vertical Distribution across Warm and Cold Fronts in CloudSat-CALIPSO Data and a General Circulation Model
}

\author{
CATHERINE M. NAUD \\ Department of Applied Physics and Applied Mathematics, Columbia University, New York, New York \\ ANTHONY D. DEL GENIO \\ NASA Goddard Institute for Space Studies, New York, New York \\ MIKE BAUER \\ Department of Applied Physics and Applied Mathematics, Columbia University, New York, New York \\ WILLIAM KOVARI \\ Center for Climate Systems Research, Columbia University, New York, New York
}

(Manuscript received 8 June 2009, in final form 9 February 2010)

\begin{abstract}
Cloud vertical distributions across extratropical warm and cold fronts are obtained using two consecutive winters of CloudSat-Cloud-Aerosol Lidar and Infrared Pathfinder Satellite Observation (CALIPSO) observations and National Centers for Environmental Prediction reanalysis atmospheric state parameters over the Northern and Southern Hemisphere oceans $\left(30^{\circ}-70^{\circ} \mathrm{N} / \mathrm{S}\right)$ between November 2006 and September 2008. These distributions generally resemble those from the original model introduced by the Bergen School in the 1920s, with the following exceptions: 1) substantial low cloudiness, which is present behind and ahead of the warm and cold fronts; 2) ubiquitous high cloudiness, some of it very thin, throughout the warm-frontal region; and 3) upright convective cloudiness near and behind some warm fronts. One winter of GISS general circulation model simulations of Northern and Southern Hemisphere warm and cold fronts at $2^{\circ} \times 2.5^{\circ} \times 32$ levels resolution gives similar cloud distributions but with much lower cloud fraction, a shallower depth of cloudiness, and a shorter extent of tilted warm-frontal cloud cover on the cold air side of the surface frontal position. A close examination of the relationship between the cloudiness and relative humidity fields indicates that water vapor is not lifted enough in modeled midlatitude cyclones and this is related to weak vertical velocities in the model. The model also produces too little cloudiness for a given value of vertical velocity or relative humidity. For global climate models run at scales coarser than tens of kilometers, the authors suggest that the current underestimate of modeled cloud cover in the storm track regions, and in particular the $50^{\circ}-60^{\circ} \mathrm{S}$ band of the Southern Oceans, could be reduced with the implementation of a slantwise convection parameterization.
\end{abstract}

\section{Introduction}

Cloud systems in midlatitude cyclones have been the object of active research for nearly a century, at least since the first comprehensive model was introduced by the Norwegian school of meteorology in the 1920s (e.g., Bjerknes and Solberg 1922; Ryan 1996; Stewart et al.

Corresponding author address: Catherine Naud, 2880 Broadway, New York, NY 10025.

E-mail: cnaud@giss.nasa.gov
1998; Posselt et al. 2008). Synoptic-scale processes (several hundred to several thousand kilometers) are resolved in general circulation models but not the processes that generate most of the cloudiness that occurs at the mesoscale level (a few to several hundred kilometers). This causes an overestimate of high-level optically thick clouds and an underestimate of optically thinner clouds (Webb et al. 2001; Zhang et al. 2005) over the midlatitude oceans. That this matters for climate models has been shown by Trenberth and Fasullo (2010), who demonstrate that the Intergovernmental Panel for Climate 
Change Fourth Assessment Report (IPCC AR4) models overestimate absorbed shortwave radiation over the Southern Oceans and consequently produce an implausible negative cloud feedback that artificially limits their climate sensitivities.

A series of studies have used satellite cloud observation composites to identify in terms of cloud-top height and optical thickness the cloud distribution in midlatitude cyclones in order to constrain general circulation models (Lau and Crane 1997; Klein and Jakob 1999; Naud et al. 2006; Field and Wood 2007; Field et al. 2008). However, full three-dimensional cloud distributions have until recently been unavailable, as passive remote sensing is limited to cloud-top or cloud-base properties depending on where the observing platform is located. High vertical resolution cloud observations from the National Aeronautic and Space Administration CloudSat (Stephens et al. 2002) and Cloud-Aerosol Lidar and Infrared Pathfinder (CALIPSO) (Winker et al. 2009) satellites have now become available since summer 2006 and allow for the first time the aggregation of cloud distributions in three dimensions within synoptic storms.

Here, we construct a composite of cloud fraction based on joint CloudSat and CALIPSO observations across a large number of warm and cold fronts that were detected in the northern and southern midlatitude oceans during two winters. The fronts are objectively identified by first using sea level pressure fields to detect propagating low pressure centers and then temperature fields to detect their fronts. The cloud composite allows us to fully characterize the vertical distribution of cloudiness across warm and cold fronts and to verify the extent to which the Bergen school model is accurate. In addition, our study allows Southern Hemisphere cyclone clouds, about which much less is known, to be compared to their more widely studied Northern counterparts. Finally, the same storm and front detection routines are applied to the Goddard Institute for Space Studies (GISS) Model E General Circulation Model. The modeled and observed cloud, dynamic, and thermodynamic vertical transects are compared, and the different possible causes for the discrepancy between model and observations are examined. The consequences of the discrepancies are finally discussed in the context of a warming climate and ramifications for future model development.

\section{Data and model}

\section{a. CloudSat-CALIPSO cloud distribution}

The NASA CloudSat (Stephens et al. 2002) and CALIPSO (Winker et al. 2009) satellites were launched in April 2006 and joined the constellation of satellites known as the A-train. The CloudSat platform carries a millimeter wavelength $94-\mathrm{GHz}$ Cloud Profiling Radar (CPR) (Im et al. 2005) and the CALIPSO satellite comprises the Cloud-Aerosol dual-wavelength 532- and 1064-nm lidar with Orthogonal Polarization (CALIOP) (Winker et al. 2007). Both active instruments allow the observation of a full cloud profile from the surface to the lower stratosphere at high vertical resolution.

Mace et al. (2009) derived a joint radar-lidar cloudbase and -top heights product at the CloudSat $\sim 1.1 \mathrm{~km}$ horizontal resolution. We use these cloud boundaries to define a cloud mask at the radar 240-m vertical and 1.1-km horizontal resolution. Cloud boundaries are defined where at least one of the two instruments detects a cloud. The radar cloud mask, described in Marchand et al. (2008) and called the geometric profile (GEOPROF), provides a succession of confidence levels that a cloud is present in a 1.1-km-240-m radar volume. The joint radar-lidar cloud product (GEOPROF-lidar) uses a confidence level of at least 20, which ensures that fewer than $5 \%$ of the radar volumes are false positive. For each radar $1.1-\mathrm{km}$ footprint, they also calculate the fraction of CALIOP profiles that contains a cloud according to the vertical feature mask (VFM) (Vaughan et al. 2009) product. When it exceeds $50 \%$ they decide that the volume in question is cloudy. Lower lidar cloud fractions tend to occur at cloud edges (e.g., see Fig. 2.f in Mace et al. 2009) where water content and signal-to-noise ratio are very low.

Because CALIPSO observations are not always available when the radar observations are, we use in these instances the original radar cloud mask (GEOPROF). This happened for $17 \%$ and $9 \%$ of all cyclones in our study for the Northern and Southern Hemispheres. These cases with lidar information missing cause a very small difference in the overall cloud fraction in the rest of this study $(<1 \%)$. Because of the high reflectivity of the surface in the radar returns, hydrometeors in the first kilometer above the surface cannot be detected with CloudSat (Marchand et al. 2008). The radar volumes found within $1.2 \mathrm{~km}$ of the surface altitudes given in the GEOPROF-lidar files (extracted from the $\sim 1 \mathrm{~km}$ GTOPO30 digital elevation model of the U.S. Geological Survey) are discarded. CloudSat sensitivity is of the order of $-30 \mathrm{~dB} z$, so optically thin clouds may not be detected by the radar alone but this is overcome when using the combined product (Mace et al. 2009). Another issue with the radar is that it cannot distinguish between different types of hydrometeor, and thus precipitation is included in the cloud mask. Haynes et al. (2009) estimate that this affects globally $\sim 12 \%$ of the columns in the midlatitude oceans (their Fig. 12). The lidar VFM product can experience difficulties in distinguishing between clouds and aerosols, so there may be some contamination 
by aerosols in the cloud mask, but mainly close to dust and smoke source regions (Liu et al. 2009) that, in the midlatitudes, are all mostly active in spring and summer (Tegen and Fung 1994; Van der Werf et al. 2006). Also, the lidar observations are noisier in the daytime, so thin cirrus are better detected at night.

Orbits during two consecutive Northern Hemisphere winters [November-March (NDJFM)] from 2006 to 2008 and two consecutive Southern Hemisphere winters [MaySeptember (MJJAS)] in 2007 and 2008 were analyzed.

\section{b. NCEP-2 reanalysis}

The National Centers for Environmental PredictionDepartment of Energy (NCEP-DOE) Atmospheric Model Intercomparison Project (AMIP-II) reanalysis atmospheric fields were chosen to obtain information on the sea level pressure along with profiles of temperature, geopotential heights, horizontal winds, vertical velocity, and relative humidity (Kanamitsu et al. 2002). This reanalysis (hereafter referred to as NCEP-2) covers the period from 1979 to 2008 at a resolution of $2.5^{\circ} \times 2.5^{\circ}$, at 17 pressure levels (L), every $6 \mathrm{~h}$. These products were extracted for the entire time period and locations mentioned in the preceding section.

\section{c. GISS Model E GCM}

The GISS Model E GCM used in this study is similar to the IPCC AR4 version fully described by Schmidt et al. (2006), with two exceptions: the version used here is at $2^{\circ} \times 2.5^{\circ} \times 32 \mathrm{~L}$ resolution (rather than the $4^{\circ} \times 5^{\circ} \times$ $23 \mathrm{~L}$ version used for AR4) and implements a diagnostic calculation of convective updraft speed and entrainment described in Del Genio et al. (2007). The stratiform cloud parameterization diagnoses large-scale cloud cover as a function of relative humidity and stability and is also described in Schmidt et al. (2006). Convective cloud cover is proportional to the cumulus mass flux and can occur at any relative humidity. The model was run using a 1975-84 sea ice and sea surface temperature climatology and an atmospheric composition from 1979. The outputs utilized here are 6-hourly samples of threedimensional convective and stratiform cloud fractions, horizontal winds, vertical velocity, temperature, geopotential heights, and relative humidity, and the twodimensional sea level pressure.

\section{Method}

\section{a. Cyclone detection}

Using the sea level pressure fields from NCEP-2 and the GCM, a method similar to that described in Bauer and Del Genio (2006) is applied to locate the midlatitude cyclone low pressure centers. This method has now been applied to the NCEP-2 reanalysis to provide a long-term climatology of midlatitude cyclones called the Modeling, Analysis and Prediction (MAP) Climatology of Midlatitude Storminess (MCMS; available online at http://gcss-dime.giss.nasa.gov/mcms/mcms.html). Low pressure centers are initially located by comparing the sea level pressure in each NCEP-2 grid cell to its eight neighboring cells and by retaining all local minima. A series of ever-narrowing filters are then used to discard centers whose properties disqualify them from being candidate cyclones. Among these filters are ones that discard purely tropical systems, overly immobile or short-lived systems, and shallow or local-scale depressions in the synoptic sea level pressure field. The end result is a set of likely cyclones that is undoubtedly biased toward the unambiguous cyclone. This is a known limitation of cyclone detection using sea level pressure fields (e.g., Sinclair 1994, 1997). However, it is appropriate to exert caution here in labeling sea level pressure features as cyclones, given the limited resolving power of the reanalysis and climate model, at capturing the full spectrum of the cyclone distribution (e.g., Condron et al. 2006; Orlanski 2008). High topography complicates both low pressure center and front detections, so we only analyze low pressure centers over oceans (using a land mask) in the $30^{\circ}-70^{\circ}$ latitude range.

For the NCEP-2 reanalysis, 6939 oceanic cyclones were detected for the two Northern Hemisphere winters and 11115 for the two Southern Hemisphere winters. However, cyclones with a center within $15^{\circ}$ and $3 \mathrm{~h}$ of a CloudSat orbit reduce this to 3686 cases for the Northern Hemisphere and 7165 for the Southern Hemisphere. About the same number of storms per year was detected using the GCM sea level pressures; that is, over only one winter 2910 storms were found over the Northern Hemisphere oceans and 5801 in the Southern Hemisphere.

\section{b. Objective front detection}

Once a low pressure center has been located, we use the technique of Hewson (1998, hereafter H98) to detect the fronts. First we calculate the potential temperature at $850 \mathrm{mb}(\theta)$ in a $\pm 25^{\circ}$ latitude-longitude box centered on the low. This variable is then used to explore where the horizontal temperature gradient is abrupt enough to reveal the location of cold and warm fronts. As in H98, we calculate the temperature gradient in each grid box $(\nabla \theta)$, then the spatial rate of change of the gradient $(\nabla|\nabla \theta|)$, and finally we calculate the "along-vector divergence" of the rate of change of the gradient, that indicates the location of fronts where it satisfies: 
(a)

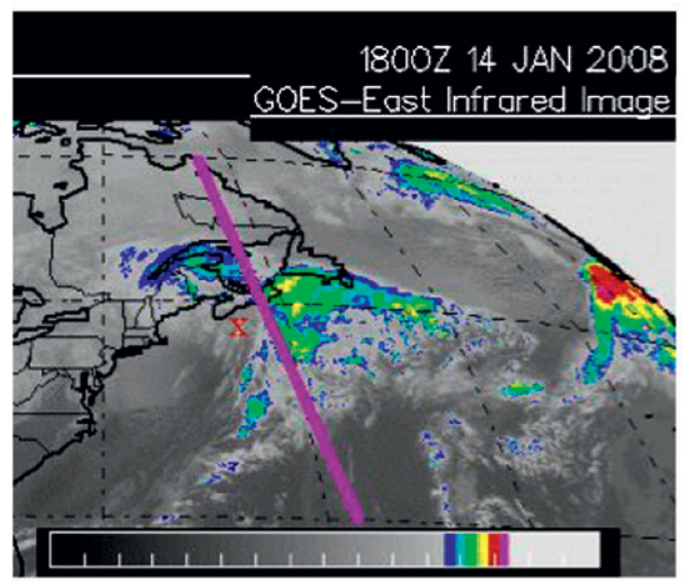

(b)

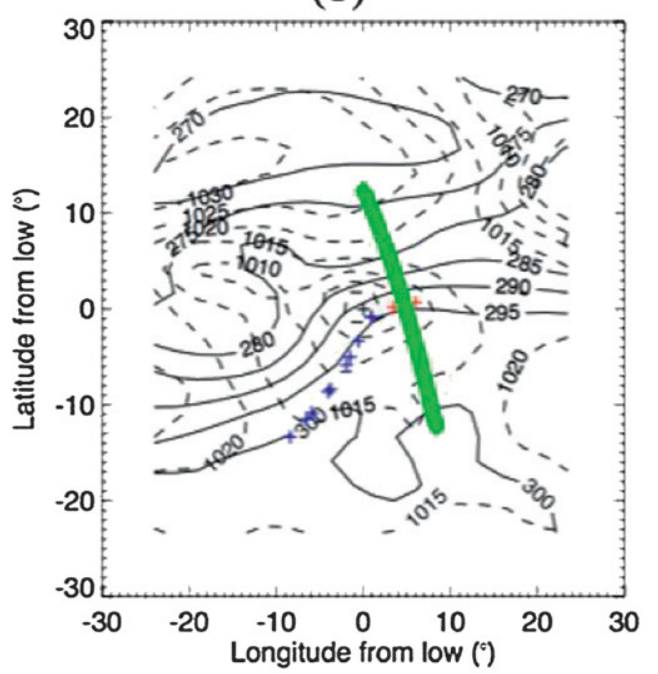

(c)

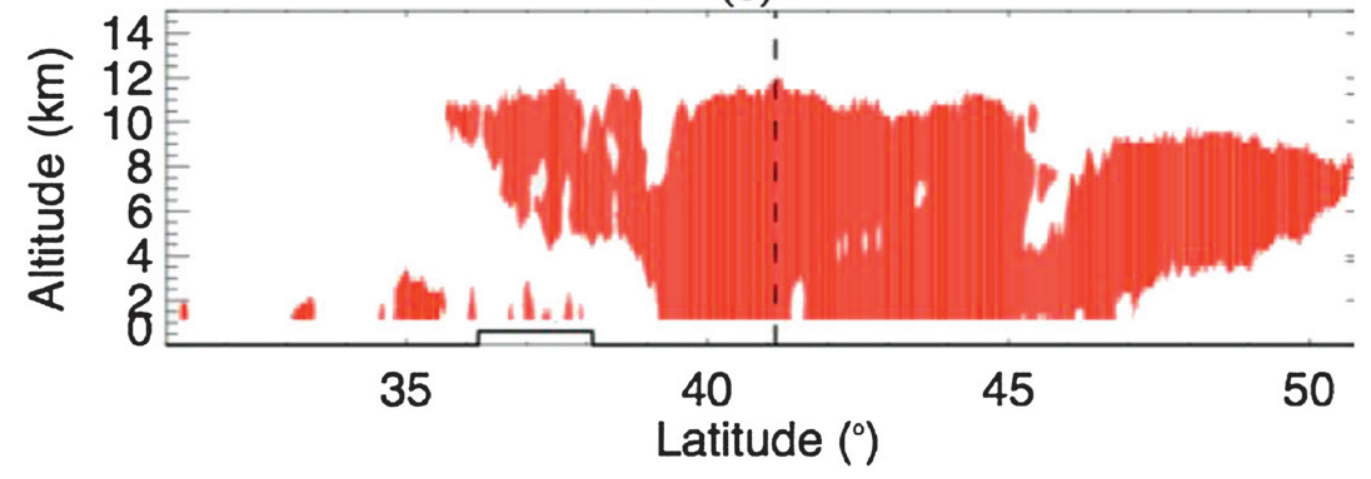

FIG. 1. (a) GOES-EAST color-enhanced infrared image for 1800 UTC 14 Jan 2008 of a midlatitude cyclone centered on $40.83^{\circ} \mathrm{N}, 65.98^{\circ} \mathrm{W}$ (red X), with a color scale that indicates temperatures at cloud top every $5^{\circ} \mathrm{C}$, starting with $-40^{\circ}$ to $-45^{\circ} \mathrm{C}$ (blue) and finishing with $-65^{\circ}$ to $-70^{\circ} \mathrm{C}$ (violet) (courtesy of the California Regional Weather center). The purple line indicates the approximate position of the CloudSat orbit; (b) NCEP-2 sea level pressure (dashed) and $850-\mathrm{mb}$ potential temperature (solid) contours centered on $40.83^{\circ} \mathrm{N}, 65.98^{\circ} \mathrm{W}$. The cold and warm fronts are shown by blue and red + symbols, respectively. The green line shows the CloudSat orbit path; (c) GEOPROFlidar cloud mask (red: hydrometeors; i.e., clouds and precipitation) along the satellite orbit with the warm front intersect marked with the dashed line.

$$
\frac{\partial(\nabla|\nabla \theta|)_{s}}{\partial s}=0
$$

with

$$
\hat{s}= \pm \frac{\nabla|\nabla \theta|}{|\nabla| \nabla \theta||}
$$

Then H98 proposes two separate masking tests to eliminate fronts where the temperature gradient does not change radically enough. The first one ensures that the rate of change of the gradient is larger than a minimum value $K_{1}$, and the second that the gradient itself is also greater than a minimum value $K_{2}$ :

$$
\begin{array}{r}
-\nabla|\nabla \theta| \cdot \frac{\nabla \theta}{|\nabla \theta|}>K_{1} \\
|\nabla \theta|_{(x, y)}+\left.m \chi|\nabla| \nabla \theta\right|_{(x, y)}>K_{2},
\end{array}
$$

where $m$ is $1 / \sqrt{2}$ and $\chi$ is the grid length. Because H98 established the thresholds $K_{1}$ and $K_{2}$ based on a $100-\mathrm{km}$ resolution dataset, we had to modify the thresholds to take into account the coarser resolution of both NCEP-2 and the GCM. For NCEP-2 the thresholds are chosen to be a factor of 2.5 smaller than in $\mathrm{H} 98\left[K_{1}=0.132^{\circ} \mathrm{C}\right.$ $(100 \mathrm{~km})^{-2}$ and $K_{2}=0.596^{\circ} \mathrm{C}(100 \mathrm{~km})^{-1}$ ] and for the $\mathrm{GCM}$ a factor of 2.25 smaller $\left[K_{1}=0.147^{\circ} \mathrm{C}(100 \mathrm{~km})^{-2}\right.$ and $\left.K_{2}=0.663^{\circ} \mathrm{C}(100 \mathrm{~km})^{-1}\right]$ to reflect the change in 
(a) NCEP-2

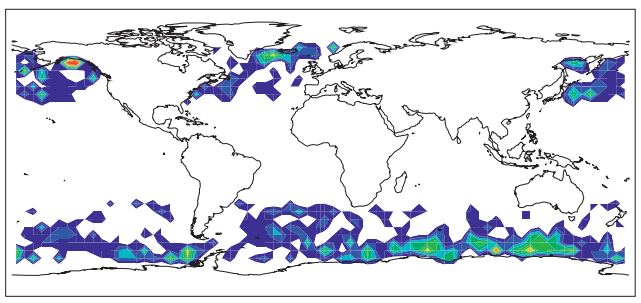

(b) GISS-GCM

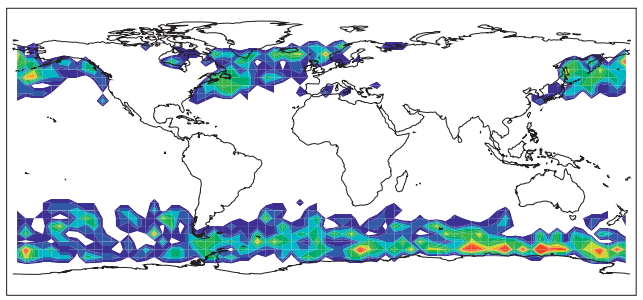

$\begin{array}{lllllllllll}0 & 1 & 2 & 3 & 4 & 5 & 6 & 7 & 8 & 9 & 10\end{array}$

Number of storms (c) CloudSat

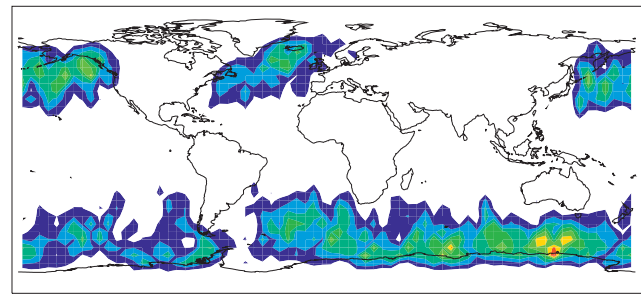

(d) GISS-GCM

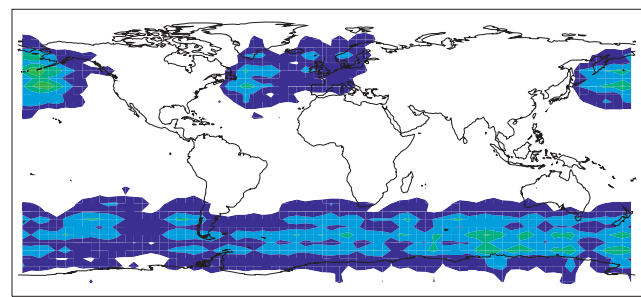

$\begin{array}{lllllllll}0 & 5 & 10 & 15 & 20 & 25 & 30 & 35 & 40\end{array}$

Density of profiles along transects $\left(x 10^{-4}\right)$

FIG. 2. Number of midlatitude cyclones detected from (a) the NCEP-2 sea level pressure for which a warm front intersects the CloudSat orbit and (b) the GCM outputs. In the right column, density of profiles per grid cell that were used along the transect perpendicular to a warm front, in (c) CloudSat-CALIPSO and (d) the GCM.

resolution from $100 \mathrm{~km}$ to $\sim 250 \mathrm{~km}$ for NCEP-2 and $\sim 225 \mathrm{~km}$ for the GCM. This is an arbitrary but necessary adjustment, as the original thresholds tend to remove most fronts. Finally, because neighboring cyclones may cause more than one warm or cold front to be detected within the $\pm 25^{\circ}$ latitude-longitude area around the low pressure center of interest, we keep only the front closest to the low pressure center. Along these fronts, we then calculate the product of the geostrophic wind velocity with the temperature gradient to obtain the local geostrophic thermal advection $\left(A_{G}=-\mathbf{V}_{G} \cdot \nabla \theta\right)$, which is positive for warm fronts and negative for cold fronts. Figure 1 shows an example, for 1800 UTC 14 January 2008 over the Atlantic Ocean, of the NCEP-2 sea level pressure and $850-\mathrm{mb}$ potential temperature contours around a low with the location of the warm and cold fronts detected using H98 and the CloudSat orbit path. It also shows the coincident Geostationary Operational Environmental Satellite (GOES-East) infrared image and the GEOPROF-lidar cloud mask along the CloudSat orbit.

Among all the NCEP-2 oceanic cyclones found during the two Northern Hemisphere winters that had a CloudSat orbit nearby, out of 3686 cyclones, 1204 warm fronts, and 1751 cold fronts could be detected. For the two
Southern Hemisphere winters, out of 7165 cyclones, 2433 warm fronts and 2628 cold fronts were detected. So for both hemispheres, a warm front could be detected for about a third of all cyclones and a cold front for closer to a half. Fronts could not be detected mainly when an occlusion was occurring or when the potential temperature gradients were too weak. In addition, a CloudSat orbit has to intersect with the warm or cold front. This happened for about a quarter to a third of all warm fronts, giving 316 transects in the Northern Hemisphere and 720 in the Southern Hemisphere. Intersects with cold fronts are not as numerous because of the typical north-south orientation of cold fronts that causes the orbit to sometimes run parallel to the fronts. In addition, as a precaution, cold fronts within the southeastern quadrant of the low pressure center were discarded to avoid occluding fronts. Consequently, 226 intersects were found in the Northern Hemisphere and 388 in the Southern Hemisphere.

Figure 2a shows the distribution of all the NCEP-2 low pressure center locations for which a warm front intersected a CloudSat orbit. The locations of the peak in storm density are comparable to those in previous studies of midlatitude storm tracks (e.g., Simmonds and Keay 2000; Hoskins and Hodges 2002, 2005; Yuan et al. 2009), despite the restrictions imposed here for the storm 
(a) NCEP-2

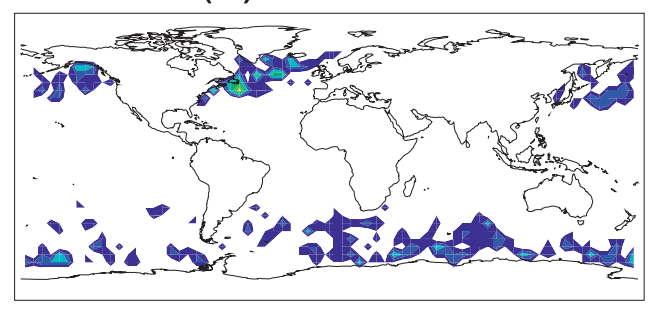

(b) GISS-GCM

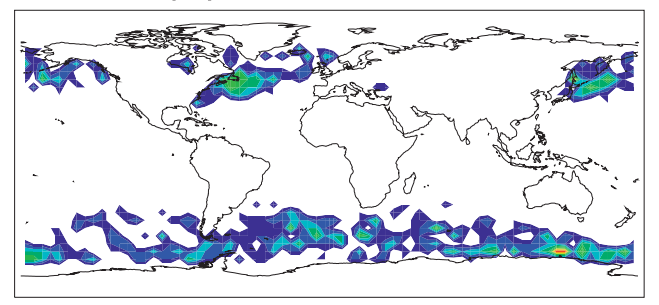

$\begin{array}{lllllllllll}0 & 1 & 2 & 3 & 4 & 5 & 6 & 7 & 8 & 9 & 10\end{array}$

Number of storms (c) CloudSat

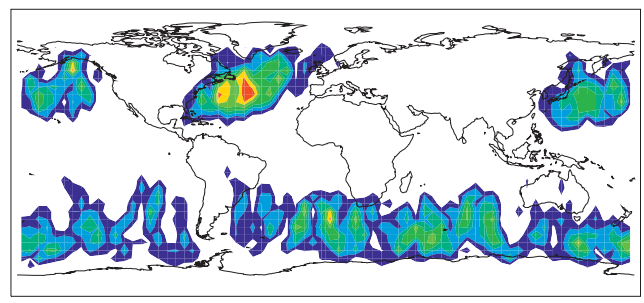

(d) GISS-GCM
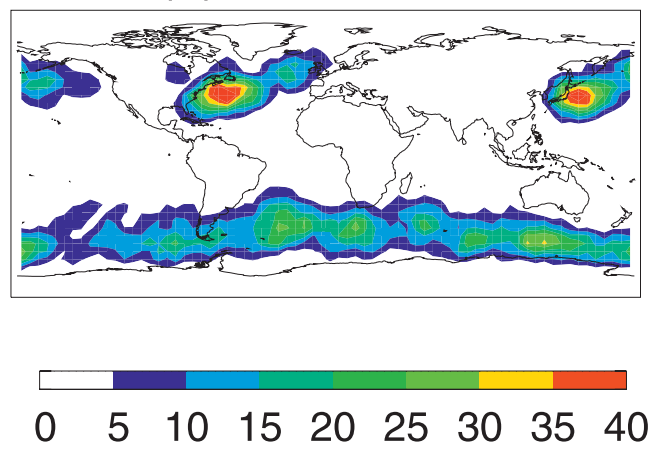

Density of profiles along transects $\left(\times 10^{-4}\right)$

FIG. 3. As in Fig. 2 but for the cold fronts.

selection (i.e., a warm front has to be detected and to intersect a CloudSat orbit). The same distribution for cyclones with an intersect between CloudSat and a cold front (Fig. 3a) resembles Fig. 2a but with a tendency for the cyclones to be displaced toward the southwest.

For the cyclones detected in the GCM outputs, out of 2910 Northern Hemisphere oceanic winter cyclones, 630 warm fronts and 599 cold fronts were detected. For the Southern Hemisphere winter cyclones, out of 5801 storms, 1304 warm fronts and 842 cold fronts were detected. Consequently, for both hemispheres, a warm front was detected for slightly less than a quarter of all cyclones and a cold front for less than a fifth, which is less than for the NCEP-2 cyclones, presumably because the GCM temperature gradients were not as pronounced.

Figure $2 b$ shows the distribution of the GCM low pressure centers for which a warm front was detected. There are more storms available with the GCM outputs since we remove NCEP-2 storms that do not have an intersect between the warm front and the CloudSat orbit, but there seems to be a good correspondence with NCEP-2 for the preferred locations of storms, such as the western side of the Atlantic Ocean, or the southern part of the Indian Ocean. Figure $3 \mathrm{~b}$ shows the distribution of cyclone centers when a cold front was detected in the GCM outputs. The southwestern displacement of the maximum in density is also visible on the GCM map.
This displacement is caused by the filtering that we apply to the candidate cold fronts when we try to avoid occlusions, for both NCEP-2 and the GCM. As a result, we favor the first steps in the life cycle of a cyclone and consequently the regions close to cyclogenesis for the Northern Hemisphere storms (e.g., Hoskins and Hodges 2002), while this is not so clear for the Southern Hemisphere (e.g., Hoskins and Hodges 2005).

\section{c. Compositing}

The objective of our study is to analyze the cloud distribution across the warm and cold fronts. We define a grid perpendicular to the front, of 250-m vertical resolution (from 0 to $15 \mathrm{~km} \mathrm{MSL}$ ) and $0.2^{\circ}$ horizontal resolution, that spans from $-10^{\circ}$ to $10^{\circ}$ distance from the front, where zero is at the front, and for the warm (cold) fronts, the negative (positive) values are in the warm sector and positive (negative) values in the cold sector. Composites of cloud fraction, relative humidity, and velocity are constructed on this grid separately for all the warm and cold front intersects.

Each CloudSat orbit that intersects a front is sampled so that the maximum distance between any point on the CloudSat segment and the surface front is $10^{\circ}$. Then the profile is assigned to a column in the composite grid according to its distance to the closest point on the 


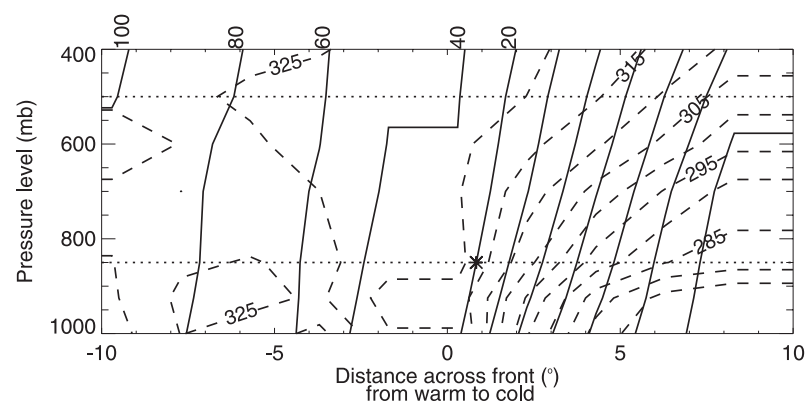

FIG. 4. For the example in Fig. 1, at 1800 UTC 14 Jan 2008 and $42.83^{\circ} \mathrm{N}, 65.98^{\circ} \mathrm{W}$ : transect across warm front, from the warm to cold sectors, of the surfaces of equal absolute geostrophic momentum (solid) and equivalent saturated potential temperature (dashed). The numbers on the top axis give the value of the $M_{g}$ surface $\left(\mathrm{m} \mathrm{s}^{-1}\right)$. The numbers along the dashed lines indicate the values of the saturated equivalent potential temperature surfaces (K). The asterisk indicates the $M_{g}$ surface along which conditional symmetric instability is occurring, between the $500-\mathrm{mb}$ and $850-\mathrm{mb}$ levels (marked with a dotted line).

surface front. The cloud fraction is calculated in each 250-m vertical bin as the total number of CloudSat profiles that contained a cloud within these $250 \mathrm{~m}$ out of the total number of CloudSat profiles found in the $0.2^{\circ}$-wide column. NCEP-2 vertical velocity, horizontal wind, and relative humidity profiles found along the CloudSat orbit are also regridded with the same vertical resolution, but at $2^{\circ}$ horizontal resolution, and then all transects thus obtained are averaged into a composite.
TABLE 1. Fraction of warm front transects that have CI, CSI, both or none in NCEP-2 and the GCM Northern and Southern Hemispheres.

\begin{tabular}{lcrrrr}
\hline \hline Dataset & Hemisphere & $\begin{array}{c}\text { CI } \\
\text { only }\end{array}$ & $\begin{array}{r}\text { CSI } \\
\text { only }\end{array}$ & $\begin{array}{c}\text { CI and } \\
\text { CSI }\end{array}$ & $\begin{array}{c}\text { No CI, } \\
\text { no CSI }\end{array}$ \\
\hline \multirow{2}{*}{ NCEP-2 } & North & $12 \%$ & $8 \%$ & $27 \%$ & $53 \%$ \\
& South & $4 \%$ & $3 \%$ & $9 \%$ & $84 \%$ \\
\multirow{2}{*}{ GCM } & North & $9 \%$ & $13 \%$ & $14 \%$ & $64 \%$ \\
& South & $8 \%$ & $2 \%$ & $9 \%$ & $81 \%$ \\
\hline
\end{tabular}

For the GCM cloud distribution across the warm and cold fronts, the same grid as for the NCEP-2 variables above is used, and individual cross sections are collected along the full length of each front. Thus, there are more transects than cyclones. All individual transects are averaged for all cyclones in the composites. A total of 2961 (2533) transects were found for the Northern Hemisphere warm (cold) fronts and 5997 (4147) for the Southern Hemisphere winter warm (cold) fronts. Transects of combined convective and stratiform cloud fraction are composited, as well as the relative humidity and the velocity fields.

Figures $2 \mathrm{c}$ and $2 \mathrm{~d}$ show a map of the density of vertical profiles found along the warm front transects, in $5^{\circ} \times 5^{\circ}$ cells, for CloudSat-CALIPSO and the GCM respectively. There are more CloudSat-CALIPSO profiles owing to the 1.1-km horizontal resolution of the measurements (versus $\sim 250 \mathrm{~km}$ for the GCM), despite the smaller

(a) $\mathrm{NH}, 316$ transects

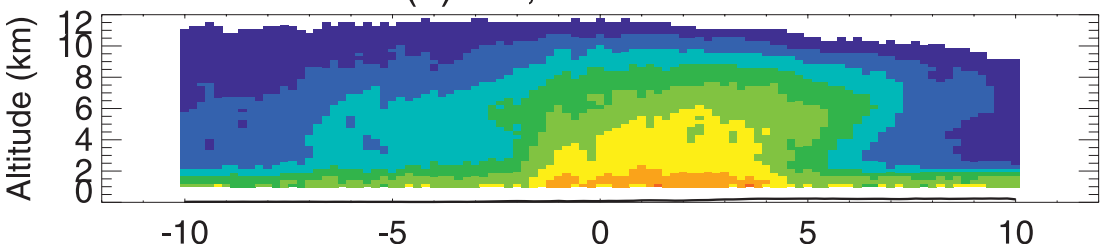

(b) $\mathrm{SH}, 720$ transects

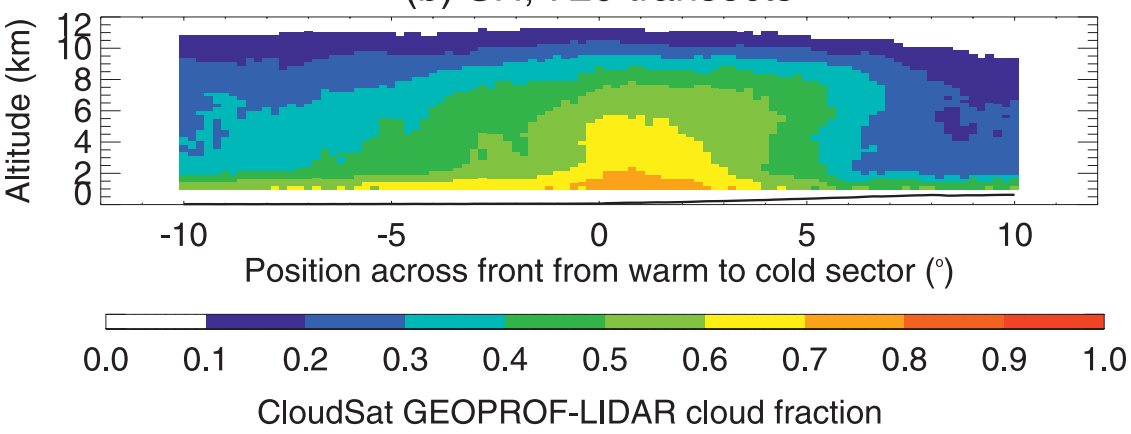

FIG. 5. CloudSat GEOPROF-lidar composite of the cloud fraction across warm fronts for (a) 316 Northern Hemisphere and (b) 720 Southern Hemisphere transects over two winters. The solid line close to the surface shows the average surface altitude for the same transects. Differences between the two hemispheres that exceed 5\% are significant at the $95 \%$ level. 
(a) $\mathrm{NH}$, no precipitation

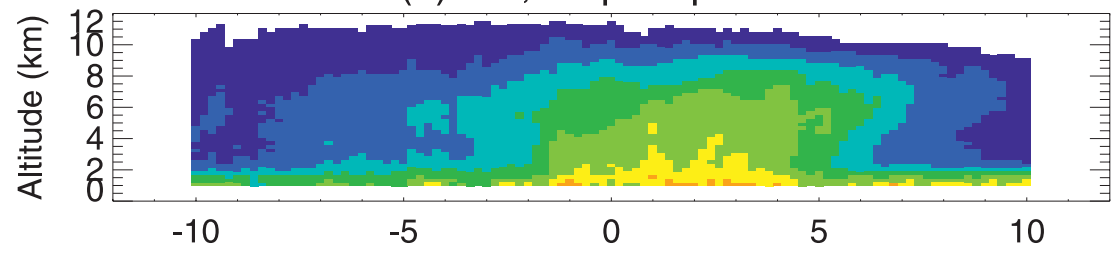

(b) $\mathrm{SH}$, no precipitation

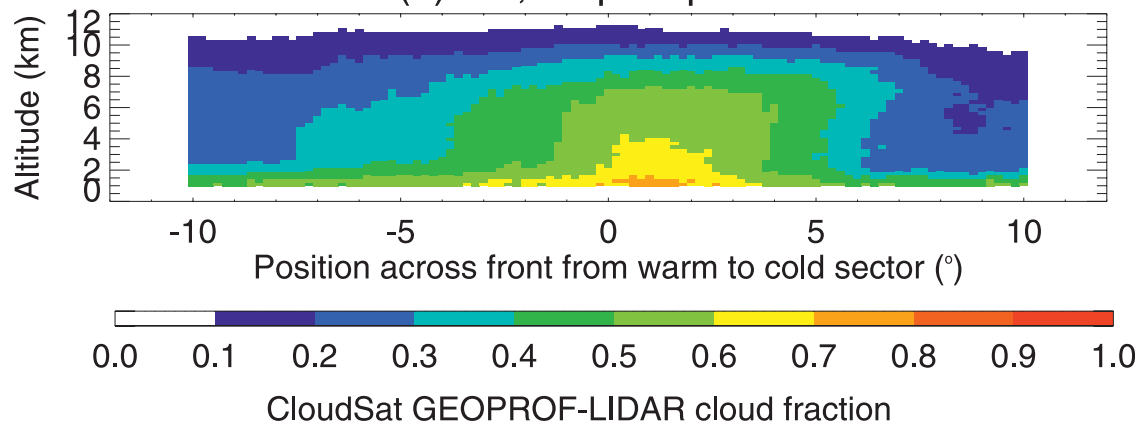

FIG. 6. As in Fig. 5 but with CloudSat-CALIPSO profiles with precipitation detected at the surface removed.

number of transects. The maps reveal how some transects overlap with land, high topography, or sea ice ( $14 \%$ of all profiles for the data, $17 \%$ for the GCM). However, because many more do not, the average height above mean sea level of the topography along all transects is below $1 \mathrm{~km}$ for both NCEP2-CloudSat and the GCM.

Figures $3 c$ and $3 d$ show the density of the profiles used for the cold front composites. It is similar to Fig. 2, but the tendency for the lows to be preferably in regions close to cyclogenesis (e.g., Hoskins and Hodges 2002, 2005) causes a slight shift of the transects equatorward. Similarly for the warm front transects, the density of profiles over land is low.

\section{d. Atmospheric state characterization across the warm fronts}

To understand how cloud distributions across warm fronts are influenced by upright convection in the warm sector or slantwise convection in the frontal zone, we consider the segment between $-7.5^{\circ}$ and $+2.5^{\circ}$ across the warm front. Within this segment we calculate the 500-850-mb vertical gradient of the saturated equivalent potential temperature $\theta_{e}^{*}=\theta \exp \left(L w^{*} / c_{p} T\right)$-where $L$ is the latent heat of vaporization, $w^{*}$ the saturation mixing ratio, $c_{p}$ the specific heat at constant pressure, and $T$ the temperature-to test for the presence of conditional instability (CI) in any column. To test for the

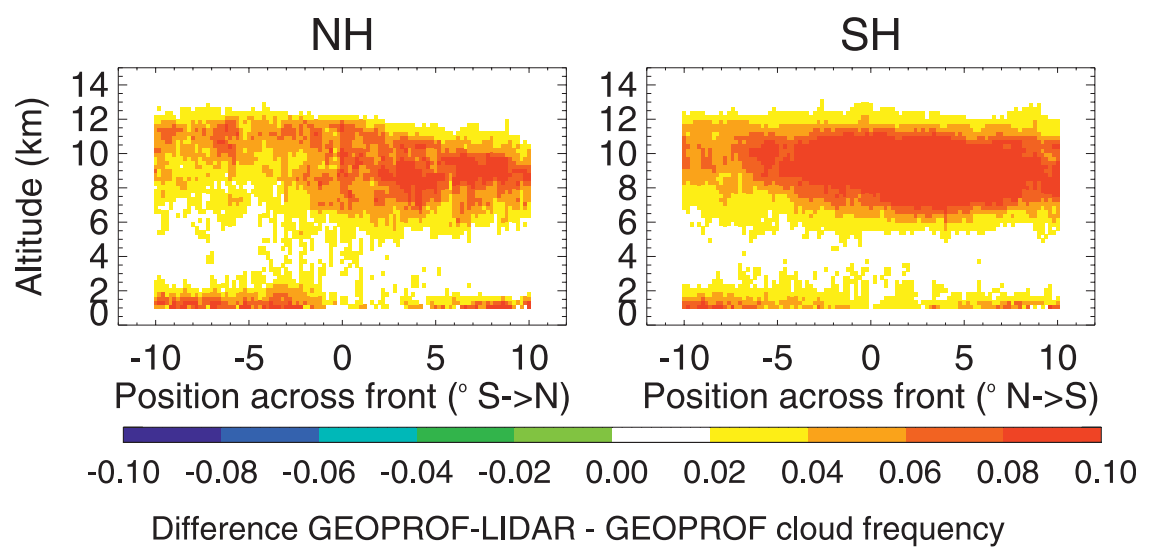

FIG. 7. Difference in observed cloud fraction composites across warm fronts between GEOPROFlidar and GEOPROF for (left) Northern and (right) Southern Hemisphere cyclones. 
(a) $\mathrm{NH}, 2961$ transects

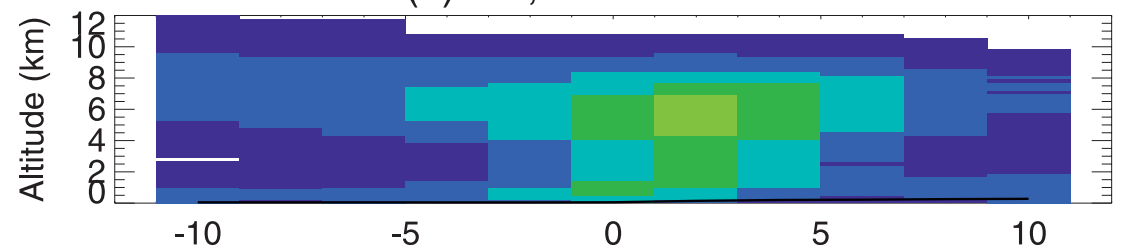

(b) $\mathrm{SH}, 5997$ transects

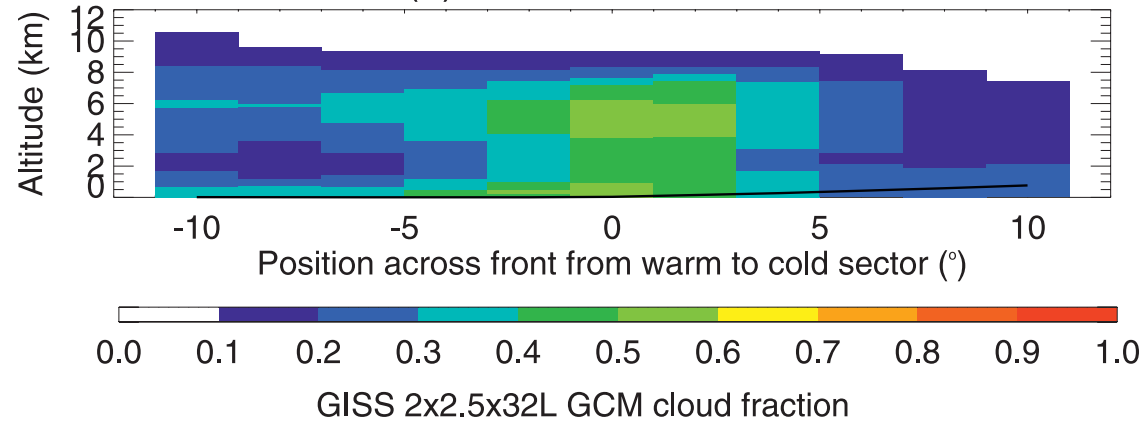

FIG. 8. As in Fig. 5 but for the GISS GCM cloud fraction over one winter.

existence of conditional symmetric instability (CSI), we calculate the same gradient between the same pressure levels but along a surface of constant geostrophic absolute momentum $M_{g}=v_{\mathrm{gs}}+f_{s}$, where $v_{\mathrm{gs}}$ is the geostrophic wind in the direction perpendicular to the temperature gradient $\left(\bar{v}_{g}=f^{-1} g \overline{\mathbf{k}} \times \bar{\nabla} Z\right)$, with $Z$ the geopotential height and $g$ the gravitational acceleration, $f$ the Coriolis parameter, and $s$ the cross-front distance increasing toward warmer air (Schultz and Schumacher 1999). A negative gradient indicates the occurrence of CI and/or CSI.
(As shown later, the situations that we analyze are also characterized by high relative humidity and upward motion, which suggests that the necessary criteria for instability above are likely to also be sufficient for upright or slantwise convection to exist.) The atmospheric state across the warm front is automatically classified as conditionally unstable if at least one vertical surface has a negative $\theta_{e}^{*}$ gradient in the $-7.5^{\circ}-2.5^{\circ}$ latitude range about the surface front, and conditionally symmetric unstable if at least one constant $M_{g}$ surface that intersects the $850-\mathrm{mb}$ (a) NCEP NH

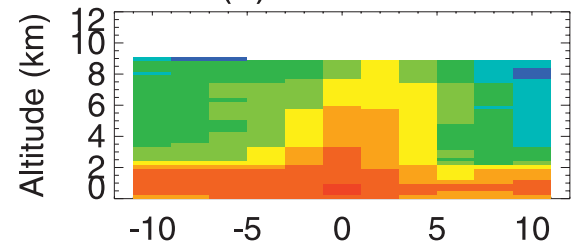

(c) NCEP SH

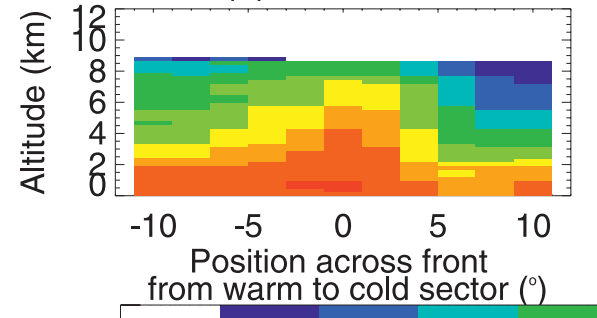

(b) GCM NH

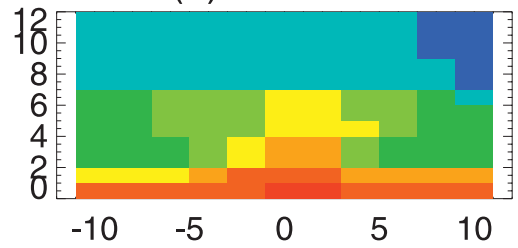

(d) GCM SH

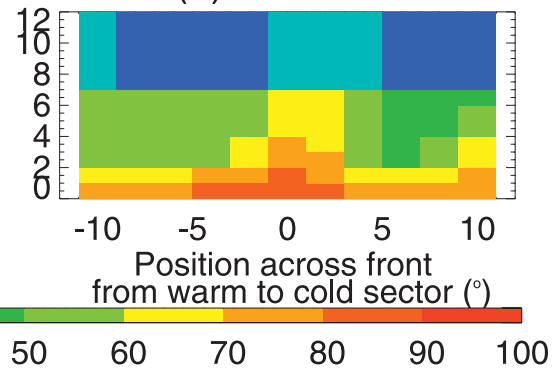

Relative humidity (\%)

FIG. 9. Composite across warm fronts of relative humidity for NCEP-2 (a) Northern and (c) Southern Hemisphere cyclones and the GISS GCM (b) Northern and (d) Southern Hemisphere cyclones. 
(a) CloudSat $\mathrm{NH}$

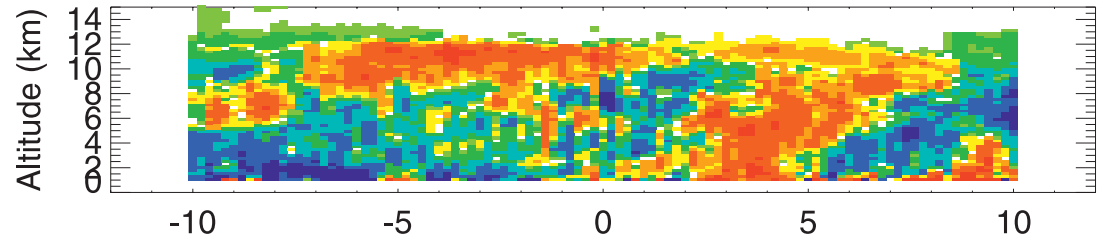

(b) $\mathrm{SH}$

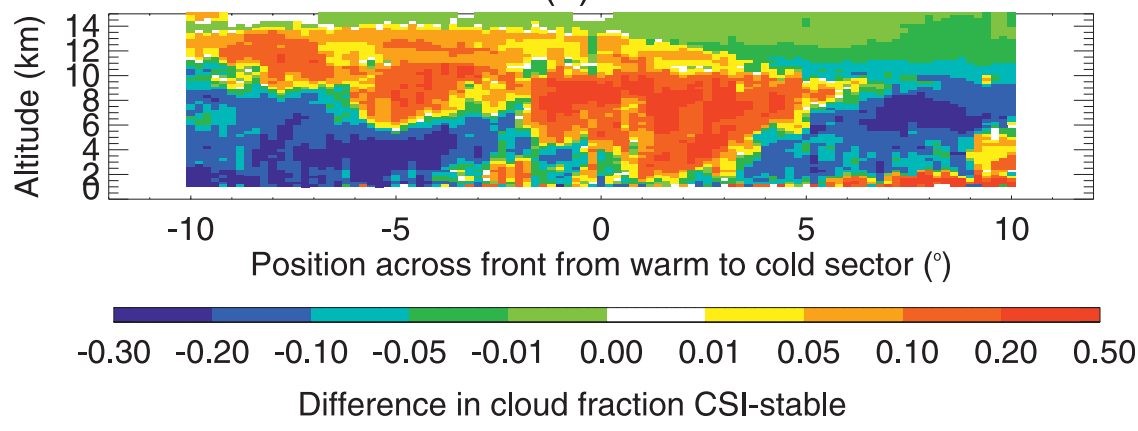

FIG. 10. Difference in CloudSat-CALIPSO cloud fraction between cyclones where CSI alone occurs and those for which no instability (neither CSI nor CI) occurs for (a) Northern and (b) Southern Hemisphere warm fronts. Differences of magnitude greater than $\sim 0.1$ are significant to the $95 \%$ level.

level in the $-2.5^{\circ}-2.5^{\circ}$ latitude range about the surface front has a negative $\theta_{e}^{*}$ gradient. Figure 4 shows the $\theta_{e}^{*}$ and $M_{g}$ contours across the warm front and the diagnosed locations of CSI for the example in Fig. 1.

Sometimes CI or/and CSI could not be diagnosed because well-defined surfaces of constant geostrophic absolute momentum between 500 and $850 \mathrm{mb}$ did not exist or because topography extending above the $850-\mathrm{mb}$ level interfered with the value of the geopotential heights or temperature. This affected less than $10 \%$ of the NCEP-2 and GCM northern and southern cyclones.

A majority of transects, $\sim 55 \%(\sim 80 \%)$ in the Northern (Southern) Hemisphere in both NCEP-2 and the GCM, had no CI or CSI (see Table 1). The NCEP-2 and (a) NCEP NH

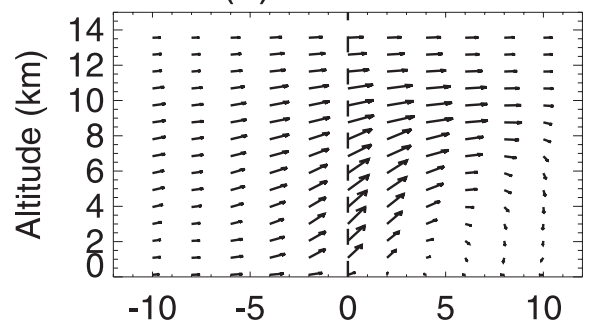

(c) NCEP $\mathrm{SH}$

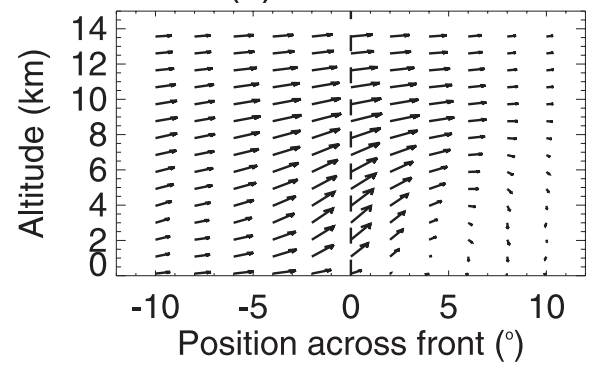

(b) GCM NH

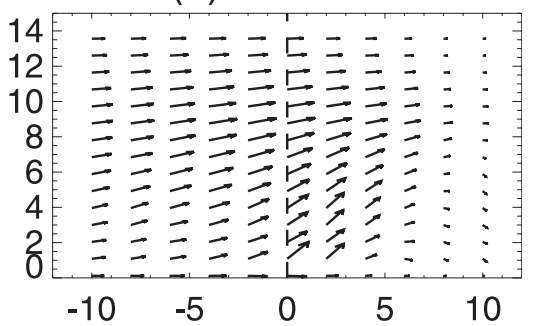

(d) GCM SH

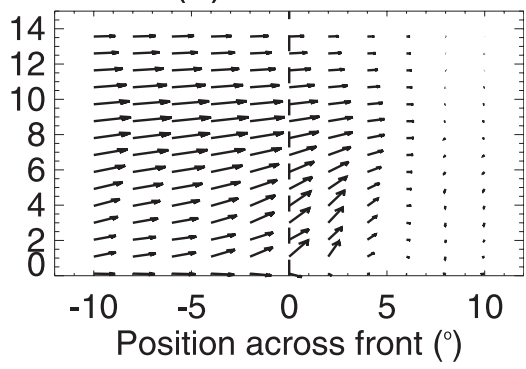

FIG. 11. Transect of vertical velocity and meridional wind across warm fronts for NCEP-2 (a) Northern and (c) Southern Hemisphere and the GCM (b) Northern and (d) Southern Hemisphere cyclones. 
(a) $\mathrm{NH}$ CloudSat-NCEP

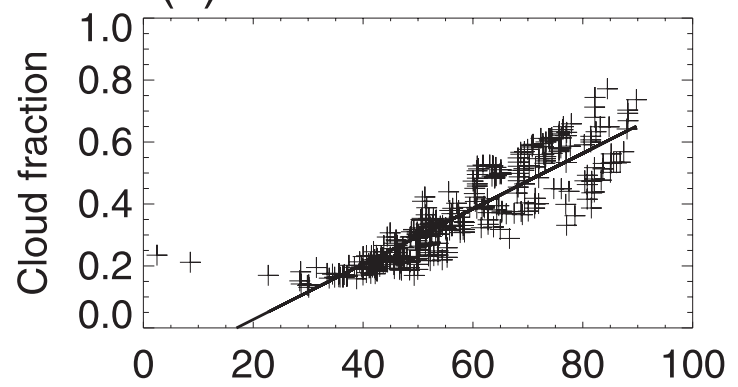

(c) SH CloudSat-NCEP

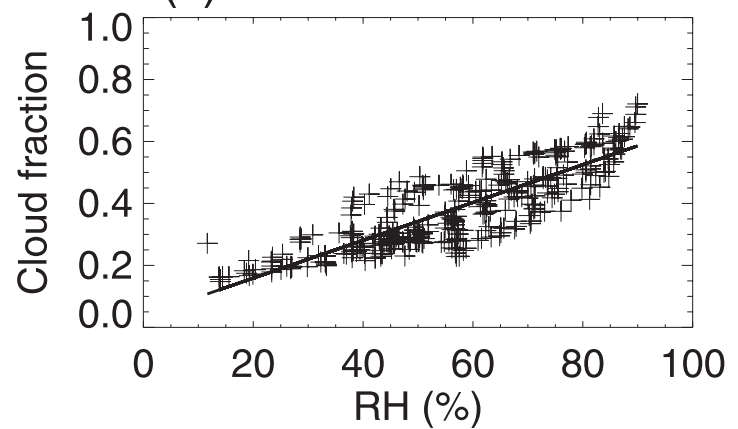

(b) NH CloudSat-NCEP

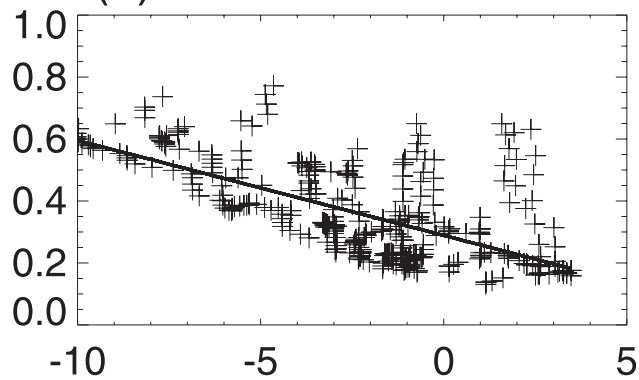

(d) SH CloudSat-NCEP

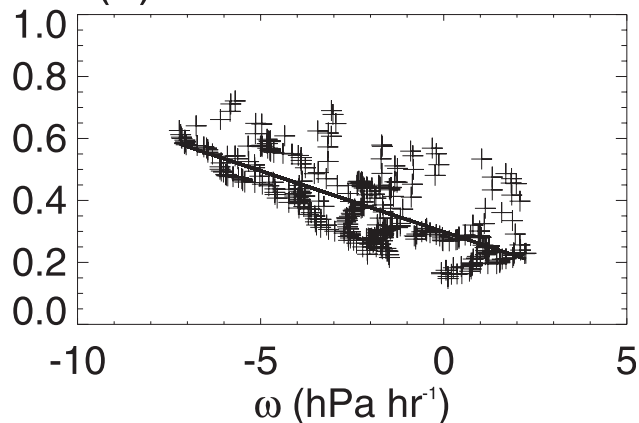

FIG. 12. Relationship between CloudSat-CALIPSO cloud fraction and NCEP-2 relative humidity across the warm fronts for the (a) Northern Hemisphere and (c) Southern Hemisphere and between CloudSat-CALIPSO cloud fraction and NCEP-2 vertical velocity for the (b) Northern Hemisphere and (d) Southern Hemisphere. The solid lines show a first-order linear regression.

GCM Northern Hemisphere transect statistics are very similar, although CSI tends to occur more often on its own than accompanied by CI in the GCM. On the contrary, CI occurs more often in the Southern Hemisphere in the GCM than NCEP-2. Overall, CSI is diagnosed more often in the Northern Hemisphere than in the Southern Hemisphere for both NCEP-2 and the GCM.

\section{Cloud distribution across warm fronts: CloudSat-CALIPSO}

CloudSat, and CALIPSO to some extent, are equally sensitive to cloud particles and precipitating particles (Marchand et al. 2008), so in this section, the term "cloud" should really be interpreted as "hydrometeors." Figure 5a shows the composite of CloudSat-CALIPSO cloud distribution across warm fronts for the Northern Hemisphere cyclones. Both in the warm sector (negative relative position) and ahead of the front (positive relative position), there is a large cloud fraction at low levels. At the front, clouds occur more often and over a wide range of altitudes. The frontal tilt can clearly be observed, up to a distance of $\sim 7^{\circ}-9^{\circ}$ in advance of the front. It is impossible for the radar to separate cloud base from precipitation below clouds; this may explain why the tilt is less well defined close to the surface front where precipitation is occurring. In the Southern Hemisphere (Fig. 5b) there are fewer low-level clouds in advance of the front, where relative humidities in the Southern Hemisphere are lower than in the Northern Hemisphere (see section 5b). High topography causes a slight overestimate of cloud fractions in the Southern Hemisphere in the 2-4-km altitude range in the $7^{\circ}-10^{\circ}$ region in advance of the warm front because a larger fraction of the transects include land surface above $1 \mathrm{~km}$ in the Southern Hemisphere: $\sim 20 \%$ of all profiles have a surface elevation above $1 \mathrm{~km}$ at $\sim 7^{\circ}$ in advance of the warm front, versus $\sim 7 \%$ in the Northern Hemisphere. The cloud fraction at the surface front is more upright than in the Northern Hemisphere warm fronts. Some of this structure may be due to contamination by precipitation. However, the same composites produced with CloudSat profiles that did not have precipitation on the ground (Haynes et al. 2009) show a similar structure in the cloud distribution, albeit with cloud fraction up to $10 \%$ lower near the surface front (Fig. 6). This frontal structure offers similarities with the downscale convective-symmetric instability "escalator-elevator" concept of Neiman et al. (1993, their Fig. 8), in which broad mesoscale regions of CSI and gently sloping convection (the escalator) are 
(a) GCM NH

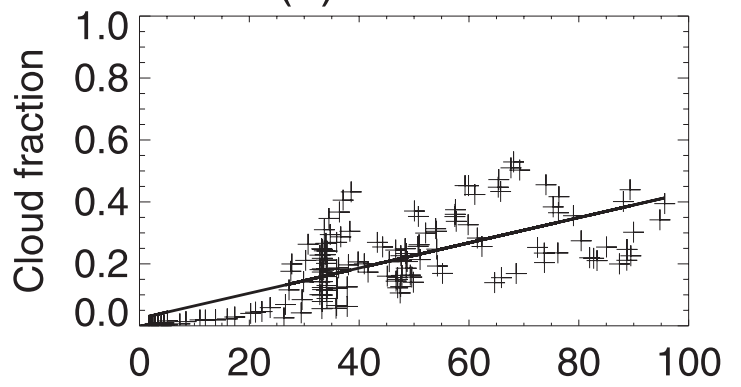

(c) GCM SH

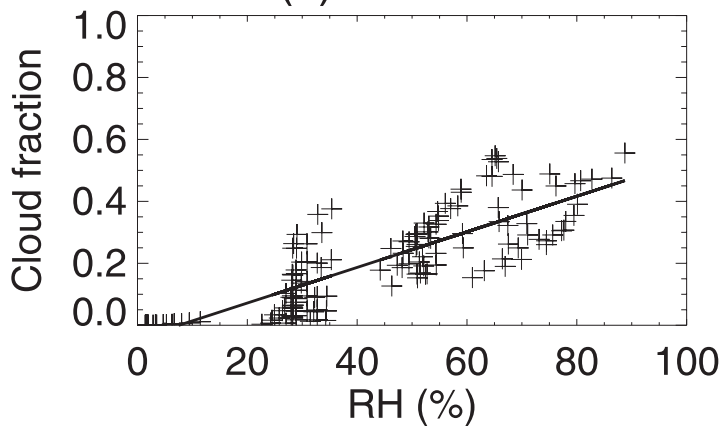

(b) GCM NH

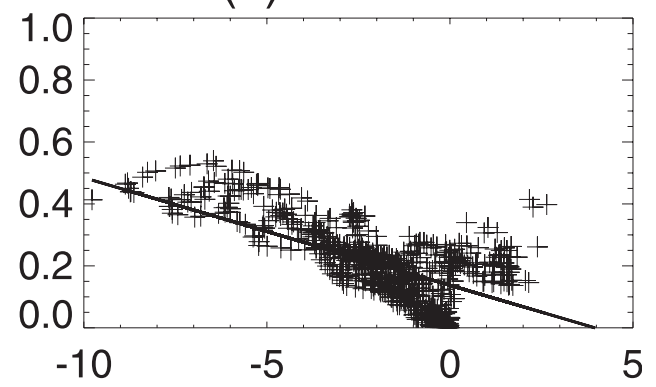

(d) GCM SH

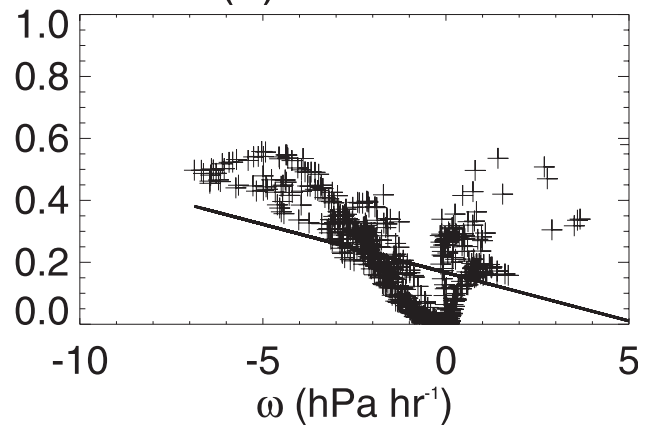

FIG. 13. As in Fig. 12 but for the GCM.

punctuated by occasional episodes of upright convection (the elevator). Figure 5 is consistent with the idea that such episodes are restricted to near the surface front in the Southern Hemisphere but spread over a larger area in northern storms. This is also consistent with the greater frequency of $\mathrm{CI}$ in the north than in the south (39\% versus $13 \%$ ) in Table 1.

Despite the large number of cases included in our composites, the basic pattern is close to what Posselt et al. (2008) found for one CloudSat orbit intersect with a warm front in the North Atlantic Ocean (their Fig. 7). The main differences are that high-level clouds in the composite do not seem to occur as often far behind the front as they do in the case study, while the composite contains more low-altitude clouds on both sides of the front.

Despite the contamination by precipitation in the radar observations and the opposite vantage points, Fig. 5 is very similar to the classical picture introduced in Norway by the Bergen school in the 1920s [e.g., Fig. 1 in Bjerknes and Solberg (1922), also reproduced in Posselt et al. (2008), their Fig. 1], with two notable differences: 1) cloud-top altitudes vary little in the frontal region in contrast with the classical picture of increasing cloudbase and -top heights in advance of a warm front, which is not surprising as the Bergen model was based on surface observations with little information on cloud tops, and 2) the classical picture has no low cloudiness away from the surface front. The latter difference may be specific to maritime storms, which have more consistent access to a surface moisture source than continental storms.

To investigate the impact of using the combined CloudSat-CALIPSO rather than the CloudSat-only cloud mask, we plotted the difference in cloud fraction across warm fronts between GEOPROF-lidar and GEOPROF

TABLE 2. Linear regression coefficients for the relation between cloud fraction and relative humidity (RH) and vertical velocity $(\omega)$ shown in Fig. 12 for CloudSat-CALIPSO and NCEP-2 and Fig. 13 for the GCM outputs. The last column also indicates the mean values of $\omega$ for the four subsets.

\begin{tabular}{llccccc}
\hline \hline & \multicolumn{2}{c}{$\mathrm{RH}$} & & \multicolumn{2}{c}{$\omega$} \\
\cline { 2 - 3 } \multicolumn{1}{c}{ Dataset } & Slope $\left(\%^{-1} \pm \sigma\right)$ & Intersect & & Slope $\left[\left(\mathrm{hPa} \mathrm{h}^{-1}\right)^{-1} \pm \sigma\right]$ & Intersect $^{\mathrm{Mean}\left(\mathrm{hPa} \mathrm{h}{ }^{-1}\right)}$ \\
\hline NCEP-2 NH & $0.009 \pm 2 \times 10^{-4}$ & -0.15 & & $-0.03 \pm 2 \times 10^{-3}$ & 0.3 & -2.3 \\
GCM-NH & $0.004 \pm 3 \times 10^{-4}$ & 0.02 & & $-0.04 \pm 2 \times 10^{-3}$ & 0.1 & -1.9 \\
NCEP-2 SH & $0.006 \pm 2 \times 10^{-4}$ & 0.04 & & $-0.04 \pm 2 \times 10^{-3}$ & 0.3 & -2.1 \\
GCM-SH & $0.006 \pm 3 \times 10^{-4}$ & -0.04 & & $-0.03 \pm 3 \times 10^{-3}$ & 0.2 & -1.2 \\
\hline
\end{tabular}


(a) $\mathrm{NH}, 226$ transects

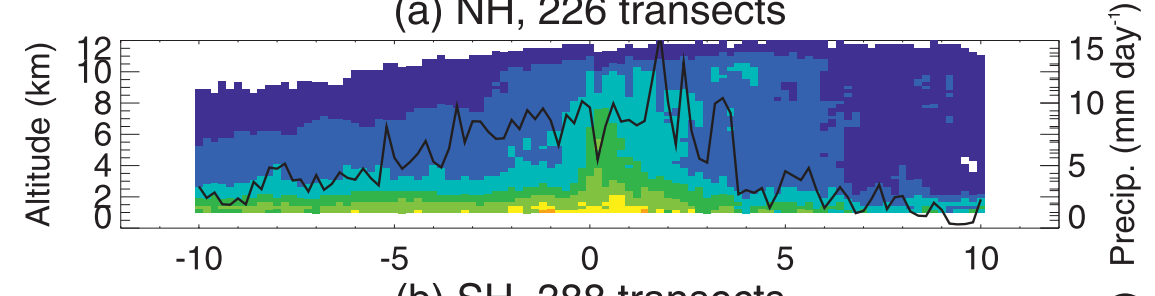

(b) $\mathrm{SH}, 388$ transects

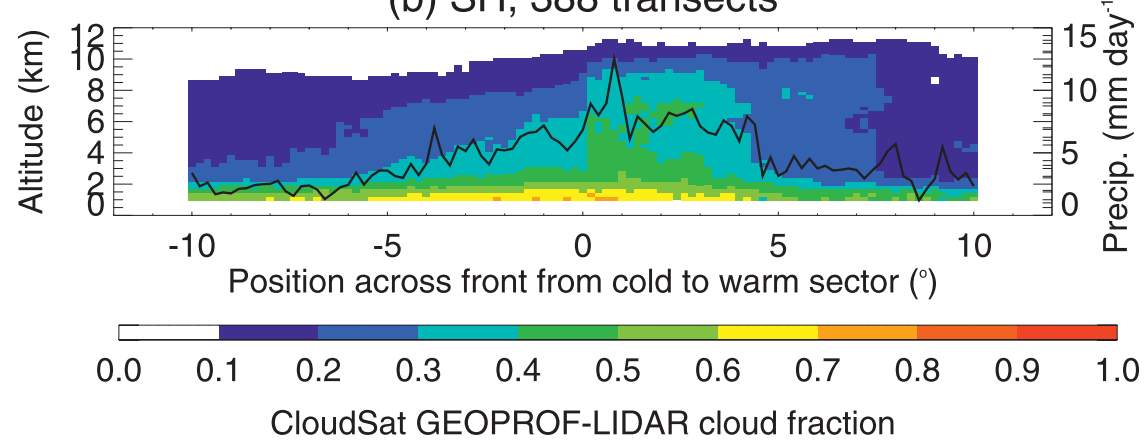

FIG. 14. As in Fig. 5 but for the cold fronts. The dark solid line shows the composite of surface precipitation rates measured with CloudSat.

for both hemispheres (Fig. 7). As expected, there are more high-level clouds when the lidar is included as well as low altitude clouds that the radar cannot detect because their liquid water content is too low or the particle size too small for the radar sensitivity [e.g., nondrizzling stratocumulus, Mace et al. (2007)]. The difference is largest in the Southern Hemisphere because of slightly lower relative humidities (section 5b) at high altitude in the south, which favors optically thinner clouds. The presence of so many lidar-only high clouds, many of which may be subvisible [these clouds contribute $4 \mathrm{~W} \mathrm{~m}^{-2}$ of the average tropical infrared heating through increased absorption of the outgoing longwave flux, according to Haladay and Stephens (2009)], combined with the surface observer vantage point on which the Bergen model was based, may explain why the classical picture does not include some of the high clouds except far in advance of the surface front.

(a) $\mathrm{NH}, 223$ transects

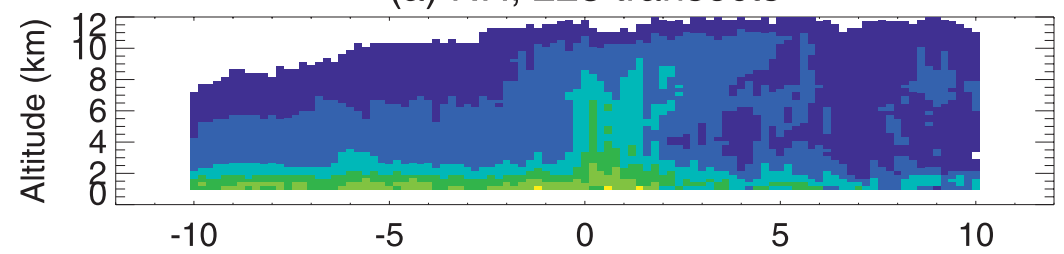

(b) $\mathrm{SH}, 388$ transects
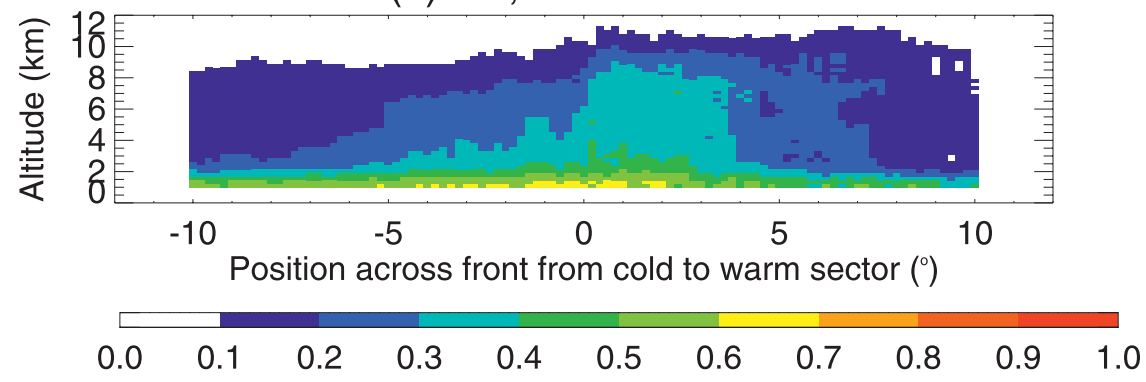

CloudSat GEOPROF-LIDAR cloud fraction

FIG. 15. As in Fig. 14 but for CloudSat-CALIPSO profiles where no precipitation is detected in the PRECIP-COLUMN product. 
(a) $\mathrm{NH}$ stable, 110 fronts

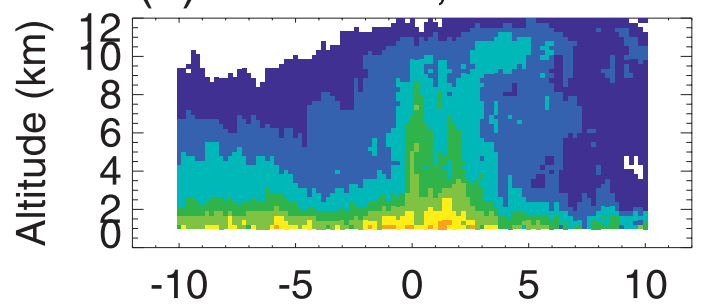

(b) $\mathrm{NH}$ unstable, 101 fronts

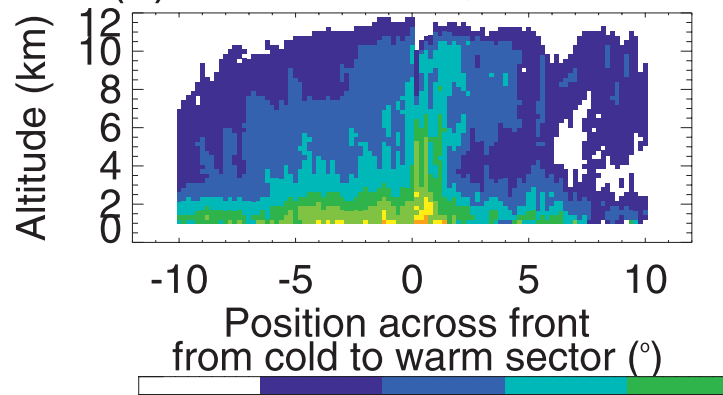

(c) SH stable, 268 fronts

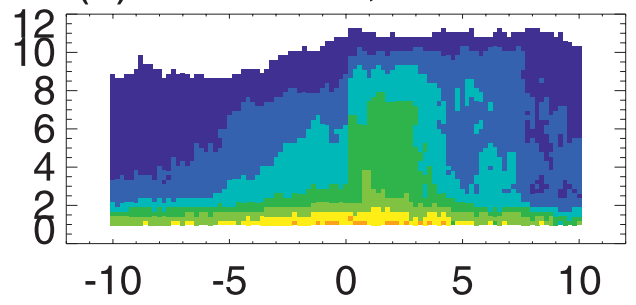

(d) $\mathrm{SH}$ unstable, 96 fronts

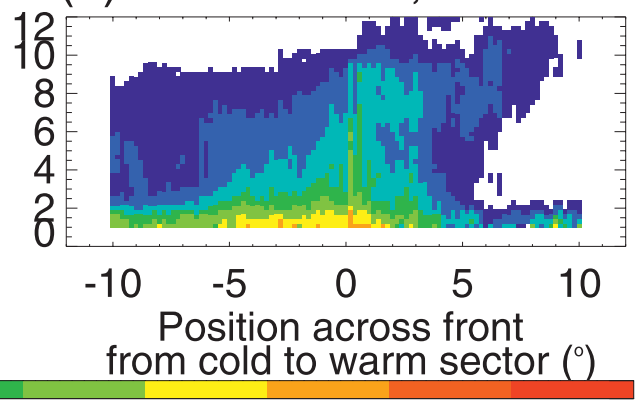

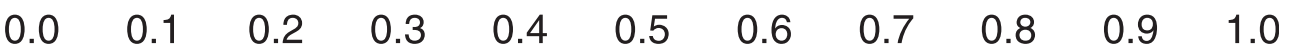 \\ GEOPROF-LIDAR cloud fraction (cold front)}

FIG. 16. As in Fig. 14 but for cold front transects separated according to the presence or absence of CI in the $\pm 2.5^{\circ}$ zone centered on the front: (a) stable and (b) unstable Northern Hemisphere fronts and (c) stable and (d) unstable Southern Hemisphere fronts.

\section{Cloud distribution in the GISS GCM}

\section{a. Modeled cloud distribution across warm fronts}

Figures $8 \mathrm{a}$ and $8 \mathrm{~b}$ show the GCM cloud fraction across warm fronts for the Northern and Southern Hemisphere cyclones. The northern frontal zone is clearly visible out to $7^{\circ}$ in advance of the front, and some low-level clouds are present in advance and after the passage of the front, but overall the cloud fraction is much lower than in the CloudSat-CALIPSO composites. Also, the GCM has a deficit of midlevel clouds in the warm sector relative to CloudSat-CALIPSO, even when compared to the composite with precipitating profiles removed (Fig. 6). The lack of midlevel clouds is a common problem of GCMs (Zhang et al. 2005). In the Southern Hemisphere, there are more clouds at the surface front and in the tilt ahead of it, and a better agreement is found with the precipitation-free CloudSat-CALIPSO composite of Fig. 6. Low-level clouds in advance of the front do not seem to occur as often as in the warm sector, which does agree with CloudSat-CALIPSO. Again the frontal zone is too narrow. The average surface height along the transects is similar to the observations (Fig. 5) and we did not find any evidence of an influence of differing topography on the difference in cloud fraction between model and observations.
We already know that at $4^{\circ} \times 5^{\circ}$ resolution the frontal tilt is too upright in the GCM (Bauer and Del Genio 2006); this behavior is still present at $2^{\circ} \times 2.5^{\circ}$ resolution. However, there are several other possible causes for the low values of cloud fraction, in particular at high levels: 1) problems with the cloud parameterization such that clouds do not form despite favorable conditions or they dissipate too quickly and 2) water vapor is not lifted to high enough altitudes because the resolved vertical velocities are too weak, as previously found in Bauer and Del Genio (2006) for the $4^{\circ} \times 5^{\circ} \times 23 \mathrm{~L}$ version of the model, or because unresolved slantwise convection is not parameterized.

\section{b. RH distribution}

To test if the cloud parameterization is responsible for the low cloud fractions, since clouds are formed based on a threshold on relative humidity (Del Genio et al. 1996), we compare composited NCEP-2 and GCM relative humidity transects across the warm fronts to see if they are similar (Fig. 9). NCEP-2 upper-level humidities, away from the surface front, are slightly lower in the Southern than in the Northern Hemisphere, consistent with the thinner clouds observed in the south noted earlier (Fig. 7). Relative humidity in the GCM is clearly too low compared to NCEP-2. In particular, the relative 
(a) NCEP NH

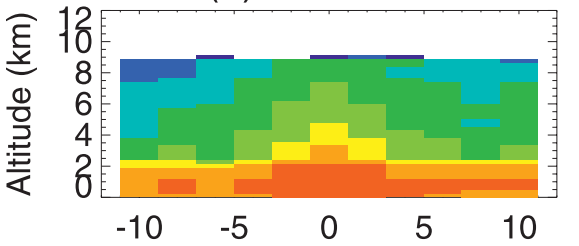

(c) NCEP SH

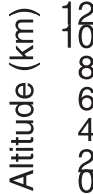

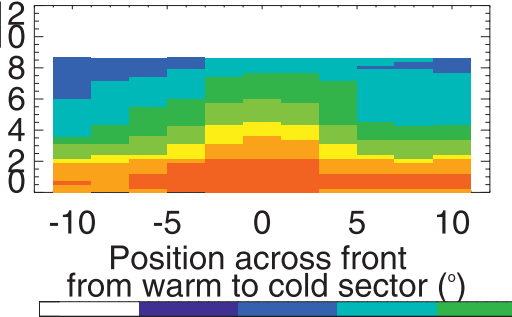

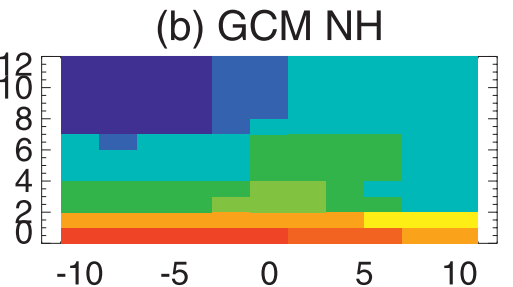

(d) GCM SH

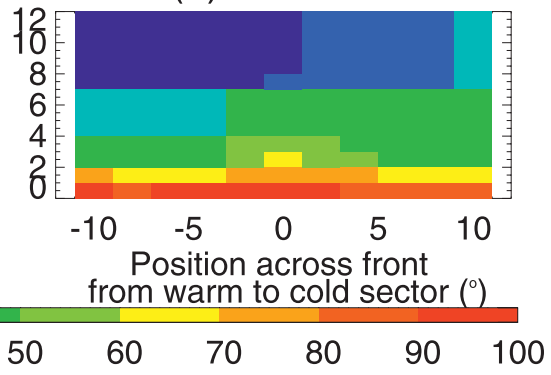

Relative humidity (\%)

FIG. 17. As in Fig. 9 but for the cold fronts.

humidity is only comparable with NCEP-2 directly above the surface and at the surface front, water vapor is not lifted to comparable altitudes. This problem has been discussed by Bauer and Del Genio (2006) for the $4^{\circ} \times$ $5^{\circ} \times 23 \mathrm{~L}$ version of the model, and Fig. 9 indicates that it is still present at this higher spatial resolution.

\section{c. Impact of conditional symmetric instability}

To examine what impact a parameterization of slantwise convection might have on the cloud fraction across warm fronts, we look at the difference in the observed cloud fraction composites between warm fronts where CSI occurs alone and those where neither CSI nor CI occurs (Fig. 10). For both hemispheres, more clouds are present in the frontal zone as well as high-level clouds in the warm sector, although the location of enhanced cloud is slightly different for the Northern and Southern Hemisphere cases. Larger cloud fractions in the Southern Hemisphere warm sector, about $5^{\circ}$ from the surface front may indicate possible contamination by a nearby cold front or another warm front. This figure suggests that a parameterization of slantwise convection might produce larger cloud fractions in the GCM frontal zone.

\section{d. Velocity distribution}

We have already noted in section $5 b$ that the high humidity values do not seem to be elevated enough in the frontal zone. Bauer and Del Genio (2006) found that the GISS GCM $4^{\circ} \times 5^{\circ} \times 23 \mathrm{~L}$ resolution vertical velocities were weaker than the ECMWF reanalysis in the frontal region of midlatitude cyclones (their Fig. 10). Figure 11 of the present paper shows the velocity transects for NCEP-2 and the GCM Northern and Southern Hemisphere warm fronts. The GCM velocity field resembles the NCEP-2 field with an increase in vertical velocity at the front and in the frontal zone compared to the warm sector or at distances of at least $5^{\circ}$ in advance of the front.

Figure 12 shows how the composite CloudSat cloud fraction relates to the composite NCEP-2 relative humidity and vertical velocities across warm fronts for the Northern and Southern Hemispheres, and Fig. 13 shows the same for the GCM outputs. Table 2 shows linear regression values for each fit and mean vertical velocities. For both NCEP-2 and the GCM, cloud fraction increases with relative humidity and with an increase in the upward velocity $(\omega<0)$, at similar rates. However, for a given vertical velocity the GCM cloud fraction is $\sim 20 \%$ smaller than observed, indicating that the cloud parameterization is one issue. Also vigorous vertical velocities occur more often in the NCEP-2 reanalysis than in the GCM (e.g., the mean NCEP- $2 \omega$ in Table 2 is noticeably larger than that in the GCM), a limitation inherent to its coarse resolution.

\section{Cloud distribution across cold fronts}

\section{a. CloudSat-CALIPSO cloud distribution}

Of the 1751 (2628) cold fronts detected in the Northern (Southern) Hemisphere, 226 (388) had an intersect with a CloudSat orbit. The CloudSat-CALIPSO cloud distribution composites perpendicular to the cold front, from cold to warm sectors, are shown in Fig. 14. Large cloud fractions are observed throughout the troposphere 
(a) NCEP NH

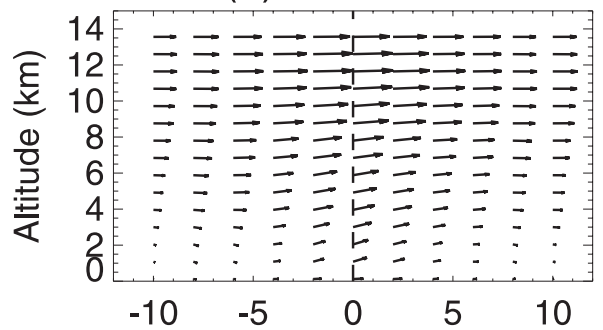

(c) NCEP SH

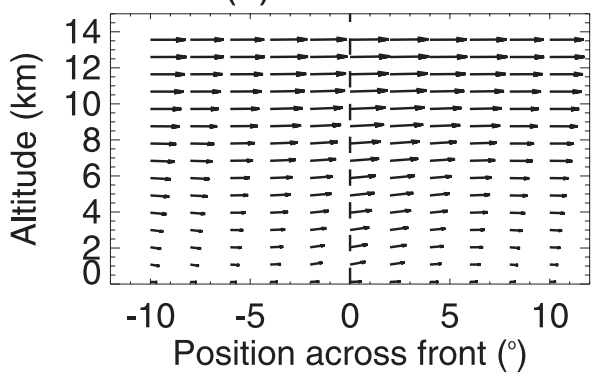

(b) GCM NH

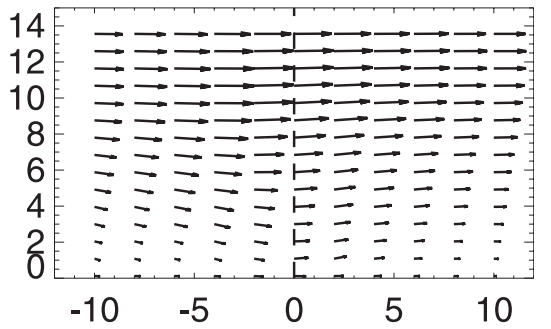

(d) GCM SH

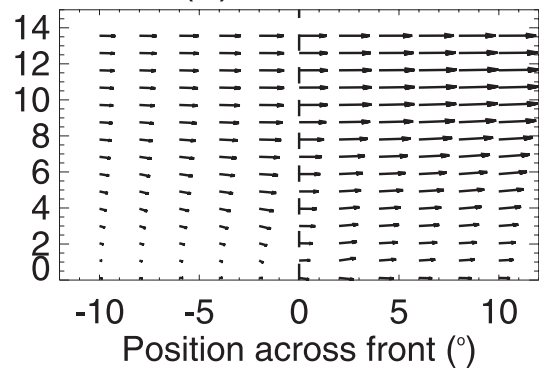

FIG. 18. As in Fig. 11 but for the cold fronts.

at the front and within $2^{\circ}$ into the warm sector for both hemispheres, but with larger cloud fractions, in particular at mid level, for the Northern Hemisphere. The anvil that extends into the warm sector is better defined for the Southern than the Northern Hemisphere cyclones. Low-level clouds are ubiquitous in the cold sector for both hemispheres, but extend to higher altitudes in the Northern Hemisphere. The low-level cloud fraction in the warm sector is larger in the Southern Hemisphere than in the Northern Hemisphere. The general cold front cloud pattern agrees fairly well with the Bergen school model, with deep convective clouds at the front that cause anvils to spread into the warm sector at high levels (see Fig. 1 in Posselt et al. 2008). Despite the absence of low-level clouds in the Bjerknes and Solberg (1922) figure, these are present in the cold sector in other representations of the model [e.g., Fig. 5 in Bjerknes (1919) or in more recent textbooks such as Fig. 5.31 in Wallace and Hobbs (1977)], in agreement with the CloudSat-CALIPSO observations.

(a) $\mathrm{NH}, 2533$ transects

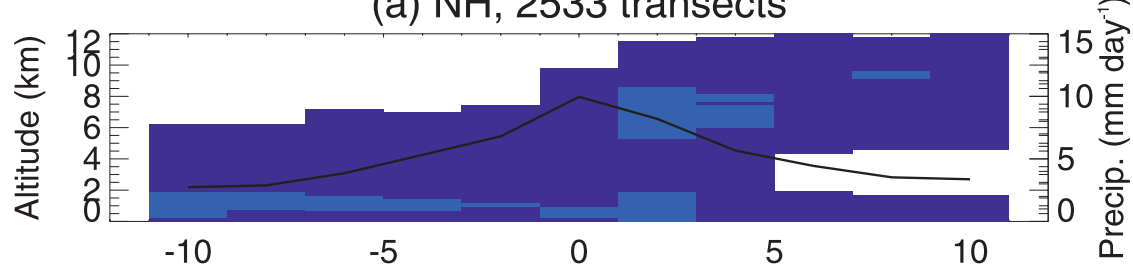

(b) $\mathrm{SH}, 4147$ transects

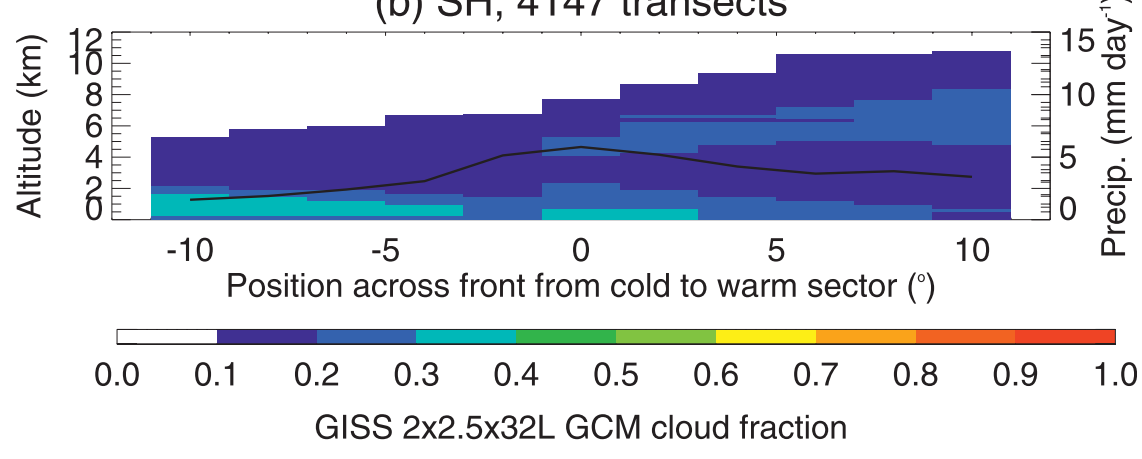

FIG. 19. As in Fig. 8 but across the cold fronts. The solid line represents the composite of modeled precipitation rates across cold fronts. 
Precipitation rates at the surface from the precipitation column (PRECIP-COLUMN) CloudSat product (Haynes et al. 2009) are also shown in Fig. 14. Large precipitation rates are observed near and ahead of the surface front, with the largest rates $2^{\circ}-4^{\circ}$ in advance of the surface front in the Northern Hemisphere and $1^{\circ}$ ahead of the surface front in the Southern Hemisphere. These peaks may indicate the presence of rainbands parallel to the cold front in the warm sector (e.g., Hobbs et al. 1980; Fig. 11.22 in Houze 1993). Precipitation also occurs in the cold sector, with greater rates in the Northern Hemisphere than the Southern Hemisphere. Cloud fraction composites for profiles with no surface precipitation (Fig. 15) have lower cloud fractions but similar cloud patterns overall.

We partitioned the cyclones according to the existence of $\mathrm{CI}$ in the $\pm 2.5^{\circ}$ zone centered on the surface front. In the Northern Hemisphere stable and unstable conditions occur almost equally often, but there are far more stable than unstable fronts in the Southern Hemisphere ( $74 \%$ versus $26 \%$ ). Figure 16 shows the cloud distribution for stable and unstable front cases. In the stable cases, the anvils are clearly defined and extend up to $5^{\circ}$ into the warm sector, but their cloud fraction decreases drastically when the front is unstable. Unstable fronts tend to display larger cloud fractions at the front and in the cold sector up to $5^{\circ}$ behind the front. The hemispheric differences in cloud fraction in Fig. 14 can thus be largely attributed to the much greater number of stable front intersects in the Southern Hemisphere. Figures $17 \mathrm{a}, \mathrm{c}$ show the NCEP-2 relative humidity distributions across the cold fronts. Relative humidities at the front above the 2-km level are greater in the Northern Hemisphere than the Southern Hemisphere, in accordance with the difference in cloud fractions. Figures 18a,c show the composite of zonal wind and vertical velocity. The general patterns are similar in the two hemispheres with descending motion in the cold sector lower altitudes and an ascending motion ahead of the front. Vertical velocities at and ahead of the surface front are larger in the Northern Hemisphere, again in accordance with the larger cloud fractions there than in the Southern Hemisphere.

\section{b. GISS GCM cloud distribution}

The number of transects across cold fronts in the GCM is 2533 for the Northern Hemisphere and 4147 for the Southern Hemisphere. The composites of the GCM cloud fraction and precipitation for both hemispheres are shown in Fig. 19. The GCM cloud fraction distribution is similar to CloudSat-CALIPSO, but with smaller cloud fractions, as seen before for the warm front composites, in particular at midlevels. The anvil part is clearly visible but extends much farther into the warm sector than in the observations. There are low-level clouds in both cold and warm sectors, with greater cloud fractions in the Southern Hemisphere cold sector. Overall, the model - data difference in cloud fraction is larger in the Northern Hemisphere than the Southern Hemisphere. Most cold front intersects are stable $(79 \%$ and $86 \%$ in the Northern and Southern Hemispheres, respectively). Figures $17 \mathrm{~b}, \mathrm{~d}$ and $18 \mathrm{~b}, \mathrm{~d}$ show the distributions of modeled relative humidity and velocity across the cold fronts. Similarly to the warm front comparison, modeled relative humidities are too low and the velocities too weak compared to NCEP-2, except in the surface layer. The relationships between cloud fraction and both relative humidity and vertical velocities along the cold front transects (not shown) are similar to those for the warm front.

The modeled precipitation in Fig. 19 is greater in the Northern Hemisphere than in the Southern Hemisphere as observed, but peaks at the front rather than ahead of it. In addition, the warm sector rainbands are not visible in the model, which is not surprising given its coarse resolution.

In summary, the model deficiencies for the cold fronts are similar to those for the warm fronts and attributable to a combination of the coarse model resolution and deficiencies in the cloud parameterization.

\section{Discussion and conclusions}

Using a midlatitude maritime cyclone climatology based on the NCEP-2 reanalysis for two consecutive winters in both Northern and Southern Hemispheres, and a technique for automated front detection proposed by Hewson (1998), we investigated the distribution of cloudiness across warm and cold fronts in CloudSatCALIPSO observations.

We found that these new cloud observations were in generally good agreement with the 1920s Bergen school model, although several updates of the classical picture are required: Clouds occur not only in the frontal region, but also 1) at low levels in advance and after the passage of the warm front and 2) at high levels almost everywhere, not just in advance of the surface warm front. In addition, deep convective cloud is present near and behind the surface warm front in some cases. We also found several subtle differences between cyclone cloud distributions over the Northern and Southern Hemisphere extratropical oceans: a greater frequency of thin high cloud, a better defined anvil in advance of cold fronts, and greater low-level cloud fractions in advance of cold fronts in the Southern Oceans.

The GISS Model E $2^{\circ} \times 2.5^{\circ} \times 32 \mathrm{~L} \mathrm{GCM}$ cloud fraction was found to be too low in the frontal region and too upright at the warm front. We find that this is partly due to an underestimate by the cloud parameterization but 
also to weak updrafts within the elevated warm air in advance of the surface warm and cold fronts that do not transport enough water vapor to high altitude for clouds to form. The GCM also underestimates midlevel cloud behind the warm front and above the surface cold front. Higher resolution would probably solve some of these problems. Precipitation is also underestimated at the surface cold front and rainbands in the warm sector in advance of the cold front are not visible.

Deficits in modeled cloud fractions in the warm and cold front zones of midlatitude cyclones could explain in part the Trenberth and Fasullo (2010) finding that absorbed shortwave radiation in the midlatitude storm track regions is higher in the IPCC AR4 GCMs than in radiation budget datasets, in particular in the $50^{\circ}-60^{\circ} \mathrm{S}$ latitude band. They find that most climate models underestimate cloud cover (causing excess solar radiation at the highly absorbing ocean surface) and cyclone frequency of occurrence in this region. This may have consequences for future climate prediction, as they find that the global climate sensitivity is negatively correlated with the excess absorbed sunlight. Consequently, we suggest that higher resolution and advances in cloud parameterization may significantly improve problems in modeled cloud distribution and the reliability of future predictions.

The part of the cloud deficiency associated with the cloud parameterization is directly tied to the use of a threshold relative humidity for stratiform cloud formation. The threshold relative humidity is, in effect, an assumption about the unresolved and unknown subgridscale distribution of relative humidity. It is explicit in diagnostic schemes such as that used in the GISS GCM, but some kind of assumption about or diagnosis of this subgrid distribution is present in every stratiform cloud parameterization. Given the general lack of knowledge about the subgrid-scale variance, GCMs tend to use a constant or height-dependent threshold humidity for all clouds, often chosen to achieve global radiation balance (the GISS GCM run analyzed here uses two values: $86 \%$ for liquid water clouds and $58 \%$ for ice clouds). The results here are evidence that this threshold is meteorological regime dependent. For boundary layer clouds, the variance that determines the threshold is controlled by turbulence (Siebesma et al. 2003), while for frontal clouds it is likely to be determined by mesoscale frontal circulations. Thus, a variable threshold relative humidity that acknowledges the likely presence of unresolved frontal uplift within synoptic-scale gridboxes of rising motion might be a simple short-term solution to the problem of deficient extratropical cloudiness.

In the long term, however, climate GCMs must address the weak and shallow resolved vertical velocities in extratropical storms and confront the issue of parameterizing the unresolved slantwise convective motions that mix water vapor upward and forward along the frontal surface. Schultz and Schumacher (1999) suggest that horizontal/ vertical resolutions of no worse than $15 \mathrm{~km} / 0.17 \mathrm{~km}$ are required to resolve the most unstable modes while, more recently, Lean and Clarke (2003) concluded that the resolution requirement was more like $2 \mathrm{~km} / 0.1 \mathrm{~km}$. Most IPCC models will not reach such resolutions in the near future, so it may be necessary to implement a slantwise convection parameterization to help solve the excess shortwave absorption problem in a realistic fashion. Candidate parameterization schemes have already been implemented in mesoscale models (Nordeng 1993). Alternatively, the objective front detection and CSI diagnosis procedures applied in our paper might serve as a basis for locating regions in GCMs that would benefit from heat and moisture mixing along constant $M_{g}$ surfaces.

Acknowledgments. This research was supported by the NASA CloudSat-CALIPSO science and modeling and analysis programs. The release 4 CloudSat data were obtained from the CloudSat Data Processing Center at the Cooperative Institute for research in the atmosphere at Colorado State University. The NCEP-DOE AMIP-II reanalysis products are available online at http://www.cdc. noaa.gov/data/gridded/data.ncep.reanalysis $2 . h t m l$. The authors thank Tim Hewson for his advice on how to adapt his method to the NCEP-2 and GCM outputs and three anonymous reviewers who helped improve this manuscript.

\section{REFERENCES}

Bauer, M., and A. D. Del Genio, 2006: Composite analysis of winter cyclones in a GCM: Influence of climatological humidity. J. Climate, 19, 1652-1672.

Bjerknes, J., 1919: On the structure of moving cyclones. Mon. Wea. Rev., 47, 95-99.

_ front theory of atmospheric circulation. Geofys. Publ., 3, 3-18.

Condron, A., G. R. Bigg, and I. A. Renfrew, 2006: Polar mesoscale cyclones in the northeast Atlantic: Comparing climatologies from ERA-40 and satellite imagery. Mon. Wea. Rev., 134, 1518-1533.

Del Genio, A. D., M.-S. Yao, W. Kovari, and K. K.-W. Lo, 1996: A prognostic cloud water parameterization for global climate models. J. Climate, 9, 270-304.

,,-- and J. Jonas, 2007: Will moist convection be stronger in a warmer climate? Geophys. Res. Lett., 34, L16703, doi:10.1029/ 2007 GL030525.

Field, P. R., and R. Wood, 2007: Precipitation and cloud structure in midlatitude cyclones. J. Climate, 20, 233-254.

_- A. Gettelman, R. B. Neale, R. Wood, P. J. Rasch, and H. Morrison, 2008: Midlatitude cyclone compositing to constrain climate model behavior using satellite observations. J. Climate, 21, 5887-5903. 
Haladay, T., and G. Stephens, 2009: Characteristics of tropical thin cirrus clouds deduced from joint CloudSat-CALIPSO observations. J. Geophys. Res., 114, D00A25, doi:10.1029/ 2008JD010675.

Haynes, J. M., T. S. L'Ecuyer, G. L. Stephens, S. D. Miller, C. Mitrescu, N. B. Wood, and S. Tanelli, 2009: Rainfall retrieval over the ocean with spaceborne W-band radar. J. Geophys. Res., 114, D00A22, doi:10.1029/2008JD009973.

Hewson, T. D., 1998: Objective fronts. Meteor. Appl., 5, 37-65.

Hobbs, P. V., T. J. Mtejka, P. H. Herzegh, J. D. Locatelli, and R. A. Houze, Jr., 1980: The mesoscale and microscale structure and organization of clouds and precipitation in midlatitude cyclones. Part I: A case study of a cold front. J. Atmos. Sci., 37, 568-596.

Hoskins, B. J., and K. I. Hodges, 2002: New perspectives on the Northern Hemisphere winter storm tracks. J. Atmos. Sci., 59, 1041-1061.

_- and - 2005: A new perspective on Southern Hemisphere storm tracks. J. Climate, 18, 4108-4129.

Houze, R. A., Jr., 1993: Cloud Dynamics. Academic Press, 570 pp.

Im, E., C. Wu, and S. L. Durden, 2005: Cloud profiling radar for the CloudSat mission. IEEE Aerosp. Electron. Syst. Mag., 20, 20-25.

Kanamitsu, M., W. Ebisuzaki, J. Woollen, S.-K. Yang, J. J. Hinilo, M. Fiorino, and G. L. Potter, 2002: NCEP-DOE AMIP-II reanalysis (R-2). Bull. Amer. Meteor. Soc., 83, 1631-1643.

Klein, S. A., and C. Jakob, 1999: Validation and sensitivities of frontal clouds simulated by the ECMWF model. Mon. Wea Rev., 127, 2514-2531.

Lau, N.-C., and M. W. Crane, 1997: Comparing satellite and surface observations of cloud patterns in synoptic-scale circulations systems. Mon. Wea. Rev., 125, 3172-3189.

Lean, H. W., and P. A. Clark, 2003: The effects of changing resolution on mesoscale modeling of line convection and slantwise circulations in FASTEX IOP16. Quart. J. Roy. Meteor. Soc., 129, 2255-2278.

Liu, Z., and Coauthors, 2009: The CALIPSO lidar cloud and aerosol discrimination: Version 2 algorithm and initial assessment of performance. J. Atmos. Oceanic Technol., 26, 1198-1213.

Mace, G. G., R. Marchand, Q. Zhang, and G. Stephens, 2007: Global hydrometeor occurrence as observed by CloudSat: initial observations from summer 2006. Geophys. Res. Lett., 34, L09808, doi:10.1029/2006GL029017.

-, Q. Zhang, M. Vaughan, R. Marchand, G. L. Stephens, C. Trepte, and D. Winker, 2009: A description of hydrometeor layer occurrence statistics derived from the first year of merged CloudSat and CALIPSO data. J. Geophys. Res., 114, D00A26, doi:10.1029/2007JD009755.

Marchand, R., G. G. Mace, T. Ackerman, and G. L. Stephens, 2008: Hydrometeor detection using CloudSat-An Earthorbiting 94-GHz cloud radar. J. Atmos. Oceanic Technol., 25, 519-533.

Naud, C. M., A. Del Genio, and M. Bauer, 2006: Observational constraints on the cloud thermodynamic phase in midlatitude storms. J. Climate, 19, 5273-5288.

Neiman, P. J., M. A. Shapiro, and L. S. Fedor, 1993: The life cycle of an extratropical marine cyclone. Part II: Mesoscale structure and diagnostics. Mon. Wea. Rev., 121, 2177-2199.

Nordeng, T. E., 1993: Parameterization of slantwise convection in numerical weather prediction models. The Representation of Cumulus Convection in Numerical Models, Meteor. Monogr., No. 46, Amer. Meteor. Soc., 195-202.

Orlanski, I., 2008: The rationale for why climate models should adequately resolve the mesoscale. High Resolution Numerical
Modeling of the Atmosphere and Ocean, K. Hamilton and W. Ohfuchi, Eds., 29-44.

Posselt, D. J., G. L. Stephens, and M. Miller, 2008: CLOUDSAT: Adding a new dimension to a classical view of extratropical cyclones. Bull. Amer. Meteor. Soc., 89, 599-609.

Ryan, B. F., 1996: On the global variation of precipitating layer clouds. Bull. Amer. Meteor. Soc., 77, 53-70.

Schmidt, G. A., and Coauthors, 2006: Present-day atmospheric simulations using GISS Model E: Comparison to in situ, satellite, and reanalysis data. J. Climate, 19, 153-192.

Schultz, D. M., and P. N. Schumacher, 1999: The use and misuse of conditional symmetric instability. Mon. Wea. Rev., 127, 27092732.

Siebesma, A. P., and Coauthors, 2003: A large eddy simulation intercomparison study of shallow cumulus convection. J. Atmos. Sci., 60, 1201-1219.

Simmonds, I., and K. Keay, 2000: Mean Southern Hemisphere extratropical cyclone behavior in the 40-year NCEP-NCAR reanalysis. J. Climate, 13, 873-885.

Sinclair, M., 1994: An objective cyclone climatology for the Southern Hemisphere. Mon. Wea. Rev., 122, 2239-2256.

1997: Objective identification of cyclones and their circulation intensity and climatology. Wea. Forecasting, 12, 591-608.

Stephens, G. L., and Coauthors, 2002: The CloudSat mission and the A-TRAIN: A new dimension to space-based observations of clouds and precipitation. Bull. Amer. Meteor. Soc., 83, 1771-1790.

Stewart, R. E., K. K. Szeto, R. F. Reinking, S. A. Clough, and S. P. Ballard, 1998: Midlatitude cyclonic cloud systems and their features affecting large scales and climate. Rev. Geophys., 36, 245-273.

Tegen, I., and I. Fung, 1994: Modeling of mineral dust in the atmosphere: Sources, transport and optical thickness. J. Geophys. Res., 99D, 22 897-22 914.

Trenberth, K. E., and J. T. Fasullo, 2010: Simulation of present day and twenty-first century energy budgets of the Southern Oceans. J. Climate, 23, 440-454.

Van der Werf, G. R., J. T. Randerson, L. Giglio, G. J. Collatz, P. S. Kasibhatla, and A. F. Arellano Jr., 2006: Interannual variability in global biomass burning emissions from 1997 to 2004. Atmos. Chem. Phys., 6, 3423-3441.

Vaughan, M. A., and Coauthors, 2009: Fully automated detection of cloud and aerosol layers in the CALIPSO lidar measurements. J. Atmos. Oceanic Technol., 26, 2034-2050.

Wallace, J. M., and P. V. Hobbs, 1977: Atmospheric Science: An Introductory Survey. Academic Press, $467 \mathrm{pp}$.

Webb, M., C. Senior, S. Bony, and J.-J. Morcrette, 2001: Combining ERBE and ISCCP data to assess clouds in the Hadley Centre, ECMWF and LMD atmospheric climate models. Climate Dyn., 17, 905-922.

Winker, D. M., W. H. Hunt, and M. J. McGill, 2007: Initial performance assessment of CALIOP. Geophys. Res. Lett., 34, L19803, doi:10.1029/2007GL030135.

, M. A. Vaughan, A. H. Omar, Y. Hu, K. A. Powell, Z. Liu, W. H. Hunt, and S. A. Young, 2009: Overview of the CALIPSO mission and CALIOP data processing algorithms. J. Atmos. Oceanic Technol., 26, 2310-2323.

Yuan, X., J. Patoux, and C. Li, 2009: Satellite-based midlatitude cyclone statistics over the Southern Ocean: 2. Tracks and surface fluxes. J. Geophys. Res., 114, D04106, doi:10.1029/2008JD010874.

Zhang, M. H., and Coauthors, 2005: Comparing clouds and their seasonal variations in 10 atmospheric general circulation models with satellite measurements. J. Geophys. Res., 110, D15S02, doi:10.1029/2004JD005021. 